This is the author's version of the work. It is posted here by permission of the AAAS for personal use, not for redistribution. The definitive version was published in Science on 22 May 2020: Vol. 368, Issue 6493, pp. 869-874, DOI:https://doi.org/10.1126/science.aaw7578

Sullivan et al. Thermal sensitivity of tropical forests

\title{
Long-term thermal sensitivity of Earth's tropical forests
}

Martin J. P. Sullivan ${ }^{1,2}$, Simon L. Lewis ${ }^{1,3}$, Kofi Affum-Baffoe ${ }^{4}$, Carolina Castilho ${ }^{5}$, Flávia Costa ${ }^{6}$, Aida Cuni Sanchez ${ }^{7,8}$, Corneille E. N. Ewango ${ }^{9,10,11}$, Wannes Hubau ${ }^{1,12,13}$, Beatriz Marimon ${ }^{14}$, Abel MonteagudoMendoza $^{15}$, Lan Qie ${ }^{16}$, Bonaventure Sonké ${ }^{17}$, Rodolfo Vasquez Martinez ${ }^{15}$, Timothy R Baker ${ }^{1}$, Roel J. W. Brienen $^{1}$, Ted R. Feldpausch ${ }^{18}$, David Galbraith ${ }^{1}$, Manuel Gloor ${ }^{1}$, Yadvinder Malhi ${ }^{19}$, Shin-Ichiro Aiba ${ }^{20}$, Miguel N. Alexiades ${ }^{21}$, Everton C. Almeida ${ }^{22}$, Edmar Almeida de Oliveira ${ }^{23}$, Esteban Álvarez Dávila ${ }^{24}$, Patricia Alvarez Loayza ${ }^{25}$, Ana Andrade ${ }^{26}$, Simone Aparecida Vieira ${ }^{27}$, Luiz Aragão $0^{28}$, Alejandro AraujoMurakami $^{29}$, Eric J.M.M. Arets ${ }^{30}$, Luzmila Arroyo ${ }^{31}$, Peter Ashton ${ }^{32}$, Gerardo Aymard C. ${ }^{33}$, Fabrício B. Baccaro $^{34}$, Lindsay F. Banin ${ }^{35}$, Christopher Baraloto ${ }^{36}$, Plínio Barbosa Camargo ${ }^{37}$, Jos Barlow ${ }^{38}$, Jorcely Barroso $^{39}$, Jean-François Bastin ${ }^{40}$, Sarah A. Batterman ${ }^{1,41,42,43}$, Hans Beeckman ${ }^{12}$, Serge K. Begne ${ }^{17,44}$, Amy C. Bennett ${ }^{44}$, Erika Berenguer ${ }^{19,38}$, Nicholas Berry ${ }^{45}$, Lilian Blanc ${ }^{46}$, Pascal Boeckx ${ }^{47}$, Jan Bogaert ${ }^{48}$, Damien Bonal $^{49}$, Frans Bongers ${ }^{50}$, Matt Bradford ${ }^{51}$, Francis Q. Brearley ${ }^{2}$, Terry Brncic ${ }^{52}$, Foster Brown ${ }^{53}$, Benoit Burban $^{54}$, José Luís Camargo ${ }^{26}$, Wendeson Castro ${ }^{55}$, Carlos Céron ${ }^{56}$, Sabina Cerruto Ribeiro ${ }^{57}$, Victor Chama Moscoso ${ }^{15}$, Jerôme Chave ${ }^{58}$, Eric Chezeaux ${ }^{59}$, Connie J. Clark ${ }^{25}$, Fernanda Coelho ${ }^{1}$, Murray Collins $^{61}$, James A. Comiskey ${ }^{62,63}$, Fernando Cornejo Valverde ${ }^{64}$, Massiel Corrales Medina ${ }^{65}$, Lola da Costa $^{66}$, Martin Dančák ${ }^{67}$, Greta C. Dargie ${ }^{1}$, Stuart Davies ${ }^{68}$, Nallaret Davila Cardozo ${ }^{69}$, Thales de Haulleville ${ }^{12,48}$, Marcelo Brilhante de Medeiros ${ }^{70}$, Jhon del Aguila Pasquel ${ }^{71}$, Géraldine Derroire ${ }^{72}$, Anthony Di Fiore ${ }^{73}$, Jean-Louis Doucet ${ }^{74}$, Aurélie Dourdain ${ }^{72}$, Vincent Droissant ${ }^{75}$, Luisa Fernanda Duque ${ }^{76}$, Romeo Ekoungoulou $^{77}$, Fernando Elias ${ }^{78}$, Terry Erwin ${ }^{79}$, Adriane Esquivel-Muelbert ${ }^{80}$, Sophie Fauset ${ }^{81}$, Joice Ferreira $^{82}$, Gerardo Flores Llampazo ${ }^{83}$, Ernest Foli ${ }^{84}$, Andrew Ford ${ }^{51}$, Martin Gilpin ${ }^{1}$, Jefferson S. Hall ${ }^{85}$, Keith C. Hamer ${ }^{86}$, Alan C. Hamilton ${ }^{87}$, David J. Harris ${ }^{88}$, Terese B. Hart ${ }^{89,90}$, Radim Hédl ${ }^{91,92}$, Bruno Herault $^{72}$, Rafael Herrera ${ }^{93}$, Niro Higuchi ${ }^{6}$, Annette Hladik ${ }^{94}$, Eurídice Honorio Coronado ${ }^{71}$, Isau Huamantupa-Chuquimaco ${ }^{95}$, Walter Huaraca Huasco ${ }^{95}$, Kathryn J. Jeffery ${ }^{96}$, Eliana Jimenez-Rojas ${ }^{97}$, Michelle Kalamandeen ${ }^{1}$, Marie-Noel Kamdem ${ }^{11,13,17,98}$, Elizabeth Kearsley ${ }^{99}$, Ricardo Keichi Umetsu ${ }^{100}$, Lip Khoon Kho Khoon ${ }^{101}$, Timothy Killeen ${ }^{102}$, Kanehiro Kitayama ${ }^{103}$, Bente Klitgaard ${ }^{104}$, Nicolas Labrière ${ }^{58}$, William Laurance ${ }^{105}$, Susan Laurance ${ }^{105}$, Miguel E. Leal ${ }^{106}$, Aurora Levesley ${ }^{1}$, Adriano J. N. Lima ${ }^{6}$, Janvier Lisingo $^{11}$, Aline P. Lopes ${ }^{107,108}$, Gabriela Lopez-Gonzalez ${ }^{1}$, Tom Lovejoy ${ }^{109}$, Jon Lovett ${ }^{1}$, Richard Lowe ${ }^{110}$, William E. Magnusson ${ }^{111}$, Jagoba Malumbres-Olarte ${ }^{112,113}$, Ângelo Gilberto Manzatto ${ }^{114}$, Ben Hur Marimon Junior $^{115}$, Andrew R. Marshall ${ }^{8,116,117}$, Toby Marthews ${ }^{118}$, Simone Matias de Almeida Reis ${ }^{14,19}$, Colin Maycock $^{119}$, Karina Melgaço ${ }^{1}$, Casimiro Mendoza ${ }^{120}$, Faizah Metali ${ }^{121}$, Vianet Mihindou ${ }^{122,123}$, William Milliken $^{104}$, Edward Mitchard ${ }^{124}$, Paulo S. Morandi ${ }^{14}$, Hannah L. Mossman ${ }^{2}$, Laszlo Nagy ${ }^{125}$, Henrique Nascimento $^{6}$, David Neill ${ }^{126}$, Reuben Nilus ${ }^{127}$, Percy Núñez Vargas ${ }^{95}$, Walter Palacios ${ }^{128}$, Nadir Pallqui Camacho $^{1,95}$, Julie Peacock ${ }^{1}$, Colin Pendry ${ }^{129}$, Maria Cristina Peñuela Mora ${ }^{130}$, Georgia C. Pickavance ${ }^{1}$, John Pipoly ${ }^{131}$, Nigel Pitman ${ }^{132}$, Maureen Playfair ${ }^{133}$, Lourens Poorter ${ }^{134}$, John R. Poulsen ${ }^{25}$, Axel D. Poulsen ${ }^{135}$, Richard Preziosi ${ }^{2}$, Adriana Prieto ${ }^{136}$, Richard Primack ${ }^{137}$, Hirma Ramírez-Angulo ${ }^{138}$, Jan Reitsma ${ }^{139}$, Maxime Réjou-Méchain ${ }^{75}$, Zorayda Restrepo Correa ${ }^{140}$, Thaiane Rodrigues de Sousa ${ }^{6}$, Lily Rodriguez Bayona $^{141}$, Anand Roopsind ${ }^{142}$, Agustín Rudas ${ }^{136}$, Ervan Rutishauser ${ }^{42,143}$, Kamariah Abu Salim ${ }^{121}$, Rafael P. Salomão ${ }^{144,145}$, Juliana Schietti ${ }^{6}$, Douglas Sheil ${ }^{146}$, Richarlly C. Silva ${ }^{57,147}$, Javier Silva Espejo ${ }^{148}$, Camila Silva Valeria ${ }^{38}$, Marcos Silveira ${ }^{57}$, Murielle Simo-Droissart ${ }^{17}$, Marcelo Fragomeni Simon ${ }^{70}$, James Singh ${ }^{149}$, Yahn Carlos Soto Shareva ${ }^{15}$, Clement Stahl ${ }^{54}$, Juliana Stropp ${ }^{150}$, Rahayu Sukri ${ }^{121}$, Terry Sunderland ${ }^{151,152}$, Martin Svátek ${ }^{153}$, Michael D. Swaine ${ }^{154}$, Varun Swamy ${ }^{155}$, Hermann Taedoumg ${ }^{17}$, Joey Talbot ${ }^{1}$, James Taplin $^{156}$, David Taylor ${ }^{157}$, Hans ter Steege ${ }^{158,159}$, John Terborgh ${ }^{25}$, Raquel Thomas ${ }^{142}$, Sean C. Thomas ${ }^{160}$, Armando Torres-Lezama ${ }^{161}$, Peter Umunay ${ }^{162,163}$, Luis Valenzuela Gamarra ${ }^{15}$, Geertje van der Heijden ${ }^{164}$, Peter van der Hout ${ }^{165}$, Peter van der Meer ${ }^{166}$, Mark van Nieuwstadt ${ }^{167}$, Hans Verbeeck ${ }^{99}$, Ronald Vernimmen ${ }^{168}$, Alberto Vicentini ${ }^{6}$, Ima Célia Guimarães Vieira ${ }^{145}$, Emilio Vilanova Torre ${ }^{169}$, Jason Vleminckx ${ }^{36}$, Vincent $\operatorname{Vos}^{171}$, Ophelia Wang ${ }^{172}$, Lee J. T. White ${ }^{123,173,174}$, Simon Willcock ${ }^{175}$, John T. Woods $^{176}$, Verginia Wortel ${ }^{177}$, Kenneth Young ${ }^{178}$, Roderick Zagt ${ }^{179}$, Lise Zemagho ${ }^{17}$, Pieter A. Zuidema ${ }^{50}$, Joeri A. Zwerts ${ }^{177,180}$, Oliver L. Phillips ${ }^{1}$ 
Affiliations:

School of Geography, University of Leeds, Leeds, UK

Department of Natural Sciences, Manchester Metropolitan University, Manchester, UK

Department of Geography, University College London, London, UK

Mensuration Unit, Forestry Commission of Ghana, Kumasi, Ghana

Embrapa Roraima, Brazilian Agricultural Research Corporation (EMBRAPA), Brasília, Brazil

Instituto Nacional de Pesquisas da Amazônia (INPA), Manaus, Brazil

Department of Ecosystem Science and Sustainability, Colorado State University, USA

Department of Environment and Geography, University of York, York, UK

DR Congo Programme, Wildlife Conservation Society, Kisangani, Democratic Republic of Congo

Centre de Formation et de Recherche en Conservation Forestiere (CEFRECOF), Epulu, Democratic Republic of Congo

Faculté de Gestion de Ressources Naturelles Renouvelables, Université de Kisangani, Kisangani, Democratic Republic of Congo

Service of Wood Biology, Royal Museum for Central Africa, Tervuren, Belgium

Department of Environment, Laboratory of Wood Technology (Woodlab), Ghent University, Ghent, Belgium

Faculdade de Ciências Agrárias, Biológicas e Sociais Aplicadas, Universidade do Estado de Mato Grosso, Nova Xavantina-MT, Brazil Jardín Botánico de Missouri, Oxapampa, Peru

School of Life Sciences, University of Lincoln, Lincoln, UK

Plant Systematics and Ecology Laboratory, Higher Teachers' Training College, University of Yaoundé I, Yaoundé, Cameroon

Geography, College of Life and Environmental Sciences, University of Exeter, Exeter, UK

Environmental Change Institute, School of Geography and the Environment, University of Oxford, Oxford, UK

Graduate School of Science and Engineering, Kagoshima University, Japan

School of Anthropology and Conservation, University of Kent, Canterbury, UK

Instituto de Biodiversidade e Florestas, Universidade Federal do Oeste do Pará, Santarém - PA, Brazil

Universidade do Estado de Mato Grosso, Cáceres - MT, Brazil

Escuela de Ciencias Agrícolas, Pecuarias y del Medio Ambiente, National Open University and Distance, Colombia

Center for Tropical Conservation, Nicholas School of the Environment, Duke University, Durham, NC, USA

Projeto Dinâmica Biológica de Fragmentos Florestais, Instituto Nacional de Pesquisas da Amazônia, Manaus, Brazil

Universidade Estadual de Campinas, Campinas - SP, Brazil

National Institute for Space Research (INPE), São José dos Campos-SP, Brazil

Museo de Historia Natural Noel Kempff Mercado, Universidad Autónoma Gabriel René Moreno, Santa Cruz, Bolivia

Wageningen Environmental Research, Wageningen, The Netherlands

Dirección de la Carrera de Biología, Universidad Autónoma Gabriel René Moreno, Santa Cruz, Bolivia

Department of Organismic and Evolutionary Biology, Harvard University, Cambridge, MA, USA

Programa de Ciencias del Agro y el Mar, Herbario Universitario, Barinas, Venezuela

Departamento de Biologia, Universidade Federal do Amazonas, Manaus, Brazil 
International Center for Tropical Botany, Department of Biological Sciences, Florida International University, Florida, FL, USA

Centro de Energia Nuclear na Agricultura, Universidade de São Paulo, São Paulo, SP, Brazil

Lancaster Environment Centre, Lancaster University, Lancaster, UK

Centro Multidisciplinar, Universidade Federal do Acre, Cruzeiro do Sul - AC, Brazil

Institure of Integrative Biology, ETH Zurich, Zurich, Switzerland

Priestley International Centre for Climate, University of Leeds, Leeds, UK

Smithsonian Tropical Research Institute, Panama, Panama

Cary Institute of Ecosystem Studies, Millbrook, NY, USA

School of Geography, School of Geography, Leeds, UK

The Landscapes and Livelihoods Group, Edinburgh, UK

UR Forest\& Societies, CIRAD, Montpellier, France

Isotope Bioscience Laboratory-ISOFYS, Ghent University, Gent, Belgium

Gembloux Agro-Bio Tech, University of Liège, Liège, Belgium

UMR Silva, INRA, Nancy, France

Department of Forest Ecology and Forest Management Group, Wageningen University, Wageningen, The Netherlands

CSIRO, Canberra, Australia

Congo Programme, Wildlife Conservation Society, Brazzavile, Republic of Congo

Woods Hole Research Center, Falmouth, MA, USA

Ecologie des Forêts de Guyane (ECOFOG), INRA, Kourou, French Guiana

Programa de Pós-Graduação Ecologia e Manejo de Recursos Naturais, Universidade Federal do Acre, Rio Branco - AC, Brazil

Herbario Alfredo Paredes, Universidad Central del Ecuador, Quito, Ecuador

Centro de Ciências Biológicas e da Natureza, Universidade Federal do Acre, Rio Branco - AC, Brazil

Laboratoire Évolution et Diversité Biologique - UMR 5174 (CNRS/IRD/UPS), CNRS, Toulouse, France

Rougier-Gabon, Libreville, Gabon

Nicholas School of the Environment, Duke University, Durham, NC, USA

Grantham Research Institute on Climate Change and the Environment, London, UK

Inventory \& Monitoring Program, National Park Service, Fredericksburg, VA, USA

Smithsonian Institution, Washington, DC, USA

Proyecto Castaña, Made de Dios, Peru

Universidad Nacional de San Agustín de Arequipa, Arequipa, Peru

Instituto de Geociências, Faculdade de Meteorologia, Universidade Federal do Para, Belém - PA, Brazil

Faculty of Science, Department of Ecology and Environmental Sciences, Palacký University

Olomouc, Olomouc, Czech Republic

Center for Tropical Forest Science, Smithsonian Tropical Research Institute, Panama, Panama

Facultad de Ciencias Biológicas, Universidad Nacional de la Amazonía Peruana, Iquitos, Peru

Embrapa Genetic Resources \& Biotechnology, Brazilian Agricultural Research Corporation (EMBRAPA), Brasília, Brazil

Instituto de Investigaciones de la Amazonía Peruana, Iquitos, Peru

Ecologie des Forêts de Guyane (ECOFOG), CIRAD, Kourou, French Guiana 
Department of Anthropology, The University of Texas at Austin, Austin, TX, USA

Forest Resources Management, Gembloux Agro-Bio Tech, University of Liège, Liège, Belgium

AMAP Lab, IRD, CIRAD, CNRS, INRA, Univ Montpellier, Montpellier, France

Socioecosistemas y Cambio Climatico, Fundacion con Vida, Medellín, Colombia

School of Forestry, Beijing Forestry University, Beijing, China

Institute of Biological Sciences, Universidade Federal do Pará, Belém - PA, Brazil

National Museum of Natural History, Smithsonian Institute, Washington, DC, USA

School of Geography, Earth and Environmental Sciences, University of Birmingham, Birmingham, UK

School of Geography, Earth and Environmental Sciences, University of Plymouth, Plymouth, UK

Embrapa Amazônia Oriental, Brazilian Agricultural Research Corporation (EMBRAPA), Brasília, Brazil

Universidad Nacional Jorge Basadre de Grohmann (UNJBG), Tacna, Peru

Forestry Research Institute of Ghana (FORIG), Kumasi, Ghana

Smithsonian Institution Forest Global Earth Observatory (ForestGEO), Smithsonian Tropical

Research Institute, Washington, DC, USA

School of Biology, University of Leeds, Leeds, UK

128 Busbridge Lane, Godalming, Surrey, UK

Royal Botanic Garden Edinburgh, Edinburgh, UK

Lukuru Wildlife Research Foundation, Kinshasa, Democratic Republic of Congo

Division of Vertebrate Zoology, Yale Peabody Museum of Natural History, New Haven, CT, USA

Institute of Botany, Czech Academy of Sciences, Brno, Czech Republic

Department of Botany, Palacký University in Olomouc, Olomouc, Czech Republic

Instituto Venezolano de Investigaciones Científicas (IVIC), Caracas, Venezuela

Département Hommes, natures, sociétés, Muséum National d'Histoire Naturel, Paris, France

Universidad Nacional de San Antonio Abad del Cusco, Cusco, Peru

Biological and Environmental Sciences, University of Stirling, Stirling, UK

Instituto IMANI, Universidad Nacional de Colombia, Leticia, Colombia

Faculty of Science, Department of Botany and Plant Physiology, University of Buea, Buea, Cameroon

Department of Environment, Computational \& Applied Vegetation Ecology (Cavelab), Ghent

University, Ghent, Belgium

PELD, Universidade do Estado de Mato Grosso, Nova Xavantina-MT, Brazil

Tropical Peat Research Institute, Malaysian Palm Oil Board, Kuala Lumpur, Malaysia

Agteca, Santa Cruz, Bolivia

Graduate School of Agriculture, Kyoto University, Japan

Royal Botanic Gardens Kew, Richmond, London, UK

Centre for Tropical Environmental and Sustainability Science (TESS) and College of Marine and Environmental Sciences, James Cook University, Australia

Uganda Programme, Wildlife Conservation Society, Kampala, Uganda

Remote Sensing Division, National Institute for Space Research (INPE), São José dos Campos-SP, Brazil

Department of Ecology, University of Brasília, Brasília, Brazil

Environmental Science and Policy, George Mason University, Fairfax, VA, USA

Botany Department, University of Ibadan, Ibadan, Nigeria 

Brazil

cE3c - Centre for Ecology, Evolution and Environmental Changes / Azorean Biodiversity Group, Universidade dos Açores, Angra do Heroísmo, Azores, Portugal

LIBRe - Laboratory for Integrative Biodiversity Research, Finnish Museum of Natural History, University of Helsinki, Helsinki, Finland

Laboratório de Biogeoquímica Ambiental Wolfgang C. Pfeiffer, Universidade Federal de Rondônia, Porto Velho - RO, Brazil

Faculdade de Ciências Agrárias, Biológicas e Sociais Aplicadas, Universidad do Estado de Mato Grosso, Nova Xavantina-MT, Brazil

Tropical Forests and People Research Centre, University of the Sunshine Coast, Australia

Flamingo Land Ltd., North Yorkshire, UK

Centre for Ecology and Hydrology, Wallingford, UK

School of International Tropical Forestry, Universiti Malaysia Sabah, Kota Kinabalu, Malaysia

Escuela de Ciencias Forestales, Unidad Académica del Trópico, Universidad Mayor de San Simón, Sacta, Bolivia Faculty of Science, Universiti Brunei Darussalam, Brunei

Agence Nationale des Parcs Nationaux, Libreville, Gabon

Ministère de la Forêt, de la Mer, de l'Environnement, Chargé du Plan Climat, Libreville, Gabon

University of Edinburgh, Edinburgh, UK

Biologia Vegetal, Universide Estadual de Campinas, Campinas - SP, Brazil

Facultad de Ingeniería Ambiental, Universidad Estatal Amazónica, Puyo, Pastaza, Ecuador

Forest Research Centre, Sabah Forestry Department, Sepilok, Malaysia

Carrera de Ingeniería Forestal, Universidad Tecnica del Norte, Ibarra, Ecuador

Royal Botanical Garden Edinburgh, Edinburgh, UK

Universidad Regional Amazónica IKIAM, Tena, Ecuador

Public Communications and Outreach Group, Parks and Recreation Division, Oakland Park, FL, USA

Keller Science Action Center, Field Museum, Chicago, IL, USA

Centre for Agricultural Research in Suriname (CELOS), Paramaribo, Suriname

Department of Forest Ecology and Forest Management Group, Wageningen University and Research, Wageningen, The Netherlands

University of Oslo, Oslo, Norway

Instituto de Ciencias Naturales, Universidad Nacional de Colombia, Leticia, Colombia

Department of Biology, Boston University, Boston, USA

Institute of Research for Forestry Development (INDEFOR), Universidad de los Andes, Mérida,

Venezuela

Bureau Waardenburg, Culemborg, The Netherlands

Socioecosistemas y Cambio Climatico, Fundacion Con Vida, Medellín, Colombia

Centro de Conservacion, Investigacion y Manejo de Areas Naturales, CIMA Cordillera Azul, Lima, Peru

Iwokrama International Centre for Rainforest Conservation and Development, Georgetown, Guyana

Carboforexpert, Geneva, Switzerland

Universidade Federal Rural da Amazônia/CAPES, Belém - PA, Brazil

Museu Paraense Emílio Goeldi, Belém - PA, Brazil

Faculty of Environmental Sciences and Natural Resource Management, Norwegian University of Life Sciences, Ås, Norway Instituto Federal do Acre, Rio Branco - AC, Brazil 
Universidad de San Antonio Abad del Cusco, Cusco, Peru

Guyana Forestry Commission, Georgetown, Guyana

Federal University of Alagoas, Maceió, Brazil

Sustainable Landscapes and Food Systems, Center for International Forestry Research, Bogor, Indonesia Faculty of Forestry, University of British Columbia, Vancouver, Canada

Department of Forest Botany, Dendrology and Geobiocoenology, Mendel University in Brno, Brno, Czech Republic

Department of Plant \& Soil Science, School of Biological Sciences, University of Aberdeen, Aberdeen, UK

Institute for Conservation Research, San Diego Zoo, San Diego, USA

UK Research \& Innovation, Innovate UK, London

Department of Geography, National University of Singapore, Singapore, Singapore

Naturalis Biodiversity Center, Leiden, The Netherlands

Systems Ecology, VU University, Amsterdam, The Netherlands

Faculty of Forestry, University of Toronto, Toronto, Canada

Universidad de los Andes, Merida, Colombia

Wildlife Conservation Society, New York, NY, USA

Yale School of Forestry \& Environmental Studies, Yale University, New Haven, CT, USA

School of Geography, University of Notingham, Nottingham, UK

Van der Hoult Forestry Consulting, Rotterdam, The Netherlands

Van Hall Larenstein University of Applied Sciences, Velp, The Netherlands

Utrecht University, Utrecht, The Netherlands

Deltares, Delft, The Netherlands

School of Environmental and Forest Sciences, University of Washington, Seattle, OR, USA

Department of Biological Sciences, Florida International University, Florida, FL, USA

Centro de Investigación y Promoción del Campesinado, La Paz, Bolivia

School of Earth Sciences and Environmental Sustainability, Northern Arizona University, Flagstaff, AZ, USA

Institut de Recherche en Ecologie Tropicale, Libreville, Gabon

School of Natural Sciences, University of Stirling, Stirling, UK

School of Natural Sciences, University of Bangor, Bangor, UK

University of Liberia, Monrovia, Liberia

Forest Management, Centre for Agricultural Research in Suriname (CELOS), Paramaribo, Suriname

Department of Geography and The Environment, University of Texas at Austin, Austin, TX, USA

Tropenbos International, Wageningen, The Netherlands

Biology, Utrecht University, Utrecht, The Netherlands 
Sullivan et al. Thermal sensitivity of tropical forests

\section{Abstract}

2 The sensitivity of tropical forest carbon to climate is a key uncertainty in predicting global climate 3 change. While short-term drying and warming are known to impact forests it is unknown if such effects

4 translate into long-term responses. Here we analyse 590 permanent plots measured across the tropics to 5 derive the equilibrium climate controls on forest carbon. Maximum temperature is the most important 6 predictor of aboveground biomass $\left(-9.1 \mathrm{Mg} \mathrm{C} \mathrm{ha}^{-1}{ }^{\circ} \mathrm{C}^{-1}\right)$, primarily by reducing woody productivity, and

7 with a greater rate of decline in the hottest forests. Our results nevertheless reveal greater thermal 8 resilience than observations of short-term variation imply. Realising the long-term climate adaptation 9 potential of tropical forests will require both protecting them and stabilising the Earth's climate.

12 One sentence summary. Biome-wide variation in tropical forest carbon stocks and dynamics shows 13 long-term thermal resilience. 
Sullivan et al. Thermal sensitivity of tropical forests

Main text

The response of tropical terrestrial carbon to environmental change is a critical component of global climate models (1). Land-atmosphere feedbacks depend on the balance of positive biomass growth stimulation by $\mathrm{CO}_{2}$ fertilisation (i.e. $\beta$ ) and negative responses to warmer temperatures and any change in precipitation (i.e. $\gamma$ ). Yet the climate response is so poorly constrained that it remains one of the largest uncertainties in Earth system models $(2,3)$, with the temperature sensitivity of tropical land carbon stocks alone differing by $>100 \mathrm{Pg} \mathrm{C}^{\circ} \mathrm{C}^{-1}$ among models (2). Such uncertainty impedes our understanding of the global carbon cycle, limiting our ability to simulate the future of the Earth system under different long-term climate mitigation strategies. A critical long-term control on tropical land-atmosphere feedbacks is the sensitivity to climate $(\gamma)$ of tropical forests, where c. $40 \%$ of the world's vegetation carbon resides (4).

The sensitivity of tropical biomass carbon stocks, their rate of production and their persistence to environmental change can all be estimated by relating their short-term and inter-annual responses to variation in climate (5-7). These sensitivities are then used to constrain longer-term projections of climate responses (2). Such approaches typically find that higher minimum temperatures are strongly associated with slower tree growth and reduced forest carbon stocks, likely due to increased respiration at higher temperatures (7-9). Tropical forest carbon is also sensitive to precipitation (10), with, for example, elevated tree mortality occurring during drought events (11).

Yet, the sensitivity of ecosystems to inter-annual fluctuations may be an unreliable guide to their longer-term responses to climate change. Such responses will also be influenced by physiological acclimation (12), changes in demographic rates (13), and shifts in species composition (14). For example, both respiration and photosynthesis can acclimate under sustained temperature increases (15-17), and tropical trees exhibit physiological plasticity (18) and shifts in species composition (14) under sustained drought. These processes could mean that tropical forests are less sensitive to climate than estimates derived from inter-annual variability imply. An alternative, complimentary approach to assessing sensitivity to climate is to measure and analyse spatial variation in tropical ecosystems across climate gradients as a space-for-time substitution. Such biome-wide spatial variation in forest 
Sullivan et al. Thermal sensitivity of tropical forests

carbon stocks, fluxes and persistence offers a unique and largely unexplored window into the potential equilibrium sensitivity of tropical forest vegetation to warming, as it captures real-world vegetation responses that allow for physiological and ecological adaptation (12).

To assess the long-term climate controls on tropical forest growth and carbon stocks, here we have assembled, measured, and analysed a pan-tropical network of 590 permanent, long-term inventory plots (Fig. 1, see Figs. S1-2 for ability to capture biome climate space). Our analysis combines standardised measurements from across South American, African, Asian and Australian tropical lowland forests $(273,239,61$ and 17 plots respectively). For every plot we calculated aboveground carbon stocks (19). Then, to better assess the dynamic controls on aboveground carbon stocks, we also computed the rate of carbon gained by the system (aboveground woody carbon production, calculated as tree growth plus newly recruited trees, in $\left.\mathrm{MgC} \mathrm{ha}^{-1} \mathrm{yr}^{-1}\right)$, and its longevity in living biomass (carbon residence time, calculated as the ratio of stocks to gains, in years).

We find considerable variation in biomass carbon among continents, with lower stocks per unit area in South America compared with the Paleotropics even after accounting for environmental variables (Fig. 1). Continents with high carbon stocks had either large carbon gains (Asia), or long carbon residence times (Africa, Fig. 1). Because of these differences among continents, which are potentially due to differences in evolutionary history (20), we analyse the environmental drivers of spatial variation in carbon stocks while accounting for biogeographical differences. We fitted linear models with explanatory variables representing hypothesised mechanistic controls of climate on tropical forest carbon (Table S1). We also included soil covariates, continent intercepts and eigenvectors describing spatial relationships amongst plots to account for other sources of variation (21).

Forest carbon stocks were most strongly related to maximum temperature $\left(-5.9 \%\right.$ per $1{ }^{\circ} \mathrm{C}$ increase in maximum temperature, $95 \% \mathrm{CI}=-8.6$ to $-3.1 \%$, Fig. 2, equivalent to $9.1 \mathrm{Mg} \mathrm{C} \mathrm{ha}^{-1}{ }^{\circ} \mathrm{C}^{-1}$ for a stand with the mean carbon stocks in our dataset, $\left.154.6 \mathrm{Mg} \mathrm{C} \mathrm{ha}^{-1}\right)$, followed by rainfall $(+2.4 \%$ per 100 $\mathrm{mm}$ increase in precipitation in the driest quarter, $95 \% \mathrm{CI}=0.6-4.3 \%$, Fig. 2), with no statistically significant relationship with minimum temperature, wind speed or cloud cover (Fig 2). The effects of maximum temperature and precipitation are also evident in an analysis considering a wider suite of 
Sullivan et al. Thermal sensitivity of tropical forests

68

69

climate variables than those tied to hypothesised mechanisms (Fig. S3), and in an additional independent pantropical dataset of 223 single-census plots (for which carbon gains and residence time cannot be assessed, Fig. S4).

The negative effect of maximum temperature on aboveground carbon stocks mainly reflects reduced carbon gains in hotter forests $\left(-4.0 \%\right.$ per $1{ }^{\circ} \mathrm{C}, 95 \% \mathrm{CI}=-6.2$ to $-1.8 \%$, Fig. 2$)$ while the positive effect of precipitation emerges through longer carbon residence times in wetter forests $(3.3 \%$ per 100 $\mathrm{mm}, 95 \% \mathrm{CI}=0.9-5.7 \%$, Fig. 2). Carbon residence time also increased with the proportion of clay in the soil (Fig. 2). The additive effects of precipitation and temperature on carbon stocks were modified by an interaction between them $(\Delta \mathrm{AIC}=15.4$ comparing full linear model with or without interaction), with temperature effects more negative when precipitation is low (Fig. S6). The interaction was through shortening carbon residence time $(\Delta \mathrm{AIC}=11.9)$ rather than reducing carbon gains (model without interaction better, $\Delta \mathrm{AIC}=1.4$ ).

An alternative analysis using decision tree algorithms (22) also showed maximum temperature and precipitation to be important (Fig. S7). This decision tree approach, which can capture complex nonlinear relationships (22), indicated potential non-linearity in the relationships between carbon stocks and both temperature and precipitation, with the positive effect of increasing dry season precipitation on residence times strengthening when precipitation was low, and the negative effect of maximum temperature intensifying at high temperatures (Fig. S7).

We further investigated non-linearity in the temperature relationship using breakpoint regression (supported over linear regression based on lower AIC, $\Delta \mathrm{AIC}=15.0$ ), which revealed that above 32.2 ${ }^{\circ} \mathrm{C}\left(95 \% \mathrm{CI}=31.7-32.6{ }^{\circ} \mathrm{C}\right)$ the relationship between carbon stocks and maximum temperature became more negative (cooler than breakpoint: $-3.8 \%{ }^{\circ} \mathrm{C}^{-1}$, warmer than breakpoint: $-14.7 \%{ }^{\circ} \mathrm{C}^{-1}$, Fig. 3). By partitioning carbon stocks into their production and persistence we find that this nonlinearity reflects changes to carbon residence time $(\Delta \mathrm{AIC}=10.6)$ rather than gains $(\Delta \mathrm{AIC}=1.7)$. Overall, our results thus indicate two separate climate controls on carbon stocks: a negative linear effect of maximum temperature through reduced carbon gains, and a non-linear negative effect of 
Sullivan et al. Thermal sensitivity of tropical forests

94

95

96

97

maximum temperature, ameliorated by high dry-season precipitation, through reduced carbon residence time.

The effect of temperature on carbon residence time only emerges when dry season precipitation is low, so is consistent with theoretical expectations that negative effects of temperature on tree longevity are exacerbated by moisture limitation rather than being independent of it (i.e. due to increased respiration costs alone) (23). This could occur through high vapour pressure deficits in hot and dry forests increasing mortality risk by causing hydraulic stress $(23,24)$, or carbon starvation due to limited photosynthesis as a result of stomatal closure (23). Notably, the temperature-precipitation interaction we find for aboveground stocks is in the opposite direction to temperature-precipitation interactions reported for soil carbon. In soils, moisture limitation suppresses the temperature response of heterotrophic respiration (25), while in trees moisture limitation enhances the mortality risks of high temperatures.

The temperature effects on biomass carbon stocks and gains are primarily due to maximum rather than minimum temperature. This is consistent with high daytime temperatures reducing $\mathrm{CO}_{2}$ assimilation rates, for example due to increased photorespiration or longer duration of stomatal closure $(26,27)$, whereas if negative temperature effects were to have increased respiration rates there should be a stronger relationship with minimum (i.e. night-time) temperature. Critically, minimum temperature is unrelated to aboveground carbon stocks both pan-tropically and in the one continent, South America, where maximum and minimum temperature are largely decoupled $(r=0.33$; Fig. S8). While carbon gains are negatively related to minimum temperature (Fig S9) this bivariate relationship is weaker than with maximum temperature, and disappears once the effects of other variables are accounted for (Fig. 2). Finally, in Asia, the tropical region which experiences the warmest minimum temperatures of all, both carbon stocks and carbon gains are highest (Fig. 1, Fig. S11).

Overall our results suggest that tropical forests have considerable potential to acclimate and adapt to the effects of night-time minimum temperatures, but are clearly sensitive to the effects of daytime maximum temperature. This is consistent with ecophysiological observations suggesting that the acclimation potential of respiration (15) is greater than that of photosynthesis (17). The temperature 
Sullivan et al. Thermal sensitivity of tropical forests

121

122

123

124

125

126

127

128

129

130

131

132

133

134

135

136

137

138

139

140

141

142

143

144

sensitivity revealed by our analysis is also considerably weaker than the short-term sensitivities associated with inter-annual climate variation (8). For example, by relating short-term annual climate anomalies to responses in plots, the effect of a $1{ }^{\circ} \mathrm{C}$ increase in temperature on carbon gains has been estimated as more than three-fold our long-term, pantropical result (28). This stronger long-term thermal resilience is likely due to a combination of individual acclimation and plasticity (15-17), differences in species' climate responses (29) leading to shifts in community composition due to changing demographic rates (12) and the immigration of species with higher performance at high temperatures (12).

Our pantropical analysis of the sensitivity to climate of aboveground carbon stocks, gains and persistence shows that warming reduces carbon stocks and gains from woody productivity in tropical forests. Using a reference carbon stock map (30) and applying our estimated temperature sensitivity (including non-linearity) while holding other variables constant leads to a biome-wide reduction of 14.1 $\mathrm{Pg} \mathrm{C}$ in live biomass (including scaling to estimate carbon in roots) for a $1^{\circ} \mathrm{C}$ increase in maximum temperature $(95 \% \mathrm{CI}=6.9-20.7 \mathrm{Pg})$. In comparison, coupled climate-carbon cycle models (2) give a median tropical land temperature sensitivity of $53 \mathrm{Pg} \mathrm{C}^{\circ} \mathrm{C}^{-1}(95 \% \mathrm{CI}=19.7-86.3$ $\mathrm{Pg}$ ), although these also incorporate the response of heterotrophic respiration and fire. In the future, reporting Earth System Model outputs for live biomass carbon separate from other changes would assist in comparing model outcomes with direct observations.

Our results suggest that global surface temperature increases of $2^{\circ} \mathrm{C}$ above pre-industrial levels will cause a potential biome-wide loss of $35.3 \mathrm{Pg} \mathrm{C}(95 \% \mathrm{CI}=20.9-49.0 \mathrm{Pg})$ based on responses to warming from the 1970-2000 baseline (31). The greatest reductions in carbon stocks are projected in South America, where baseline temperatures and future warming are both highest (Fig. 4, Fig. S12). This warming would push $71 \%$ of the biome beyond the thermal threshold - maximum temperature of $32.2^{\circ} \mathrm{C}$ - where larger reductions in biomass are expected. Of course, growth stimulation by carbon dioxide (32) will partially or wholly offset the effect of this temperature increase, depending on both the level of atmospheric carbon dioxide that limits warming to $2^{\circ} \mathrm{C}$ above pre-industrial levels and the fertilization effect of this carbon dioxide on tropical trees. Using a variety of published estimates of 
Sullivan et al. Thermal sensitivity of tropical forests

148 the carbon dioxide fertilization effect (Table S3), partial or full amelioration is expected in the

149 Paleotropics, although reductions in forest carbon stocks are predicted in South America in all

150 scenarios (Fig. S15).

151 The long-term climate sensitivities derived from our pan-tropical field measurements incorporate

152 ecophysiological and ecological adaptation, and so provide a model-independent estimate of the long-

153 term quasi-equilibrium response of tropical vegetation to climate, which can inform long-term model

154 predictions (33). We note that the thermal adaptation measured here may not be fully realised because

155 (i) the speed of temperature rises may exceed species' adaptive capabilities, (ii) habitat fragmentation

156 may limit species' ability to track changes in the environment, and (iii) other human impacts such as

157 logging and fire can increase the vulnerability of forest carbon stocks to high temperatures.

158 Predictions based on short-term inter-annual sensitivity and our long-term pan-tropical sensitivity

159 likely represent the upper and lower bounds of transient responses to rising temperatures over the

160 coming decades. While many tropical forests are under severe threat of conversion, our results show

161 that, in the long-run, tropical forests that remain intact can continue to store high levels of carbon

162 under high temperatures. Achieving the biome-wide climate resilience potential we document

163 depends on limiting heating and on large-scale conservation and restoration to protect biodiversity and

164 allow species to move. 
Sullivan et al. Thermal sensitivity of tropical forests

167

168

169

170

171

172

173

174

175

176

177

178

179

180

181

182

183

184

185

186

187

188

189

190

\section{References and Notes}

1. P. M. Cox, R. A. Betts, C. D. Jones, S. A. Spall, I. J. Totterdell, Acceleration of global warming due to carbon-cycle feedbacks in a coupled climate model. Nature 408, 184 (2000).

2. P. M. Cox et al., Sensitivity of tropical carbon to climate change constrained by carbon dioxide variability. Nature 494, 341-344 (2013).

3. B. B. B. Booth et al., High sensitivity of future global warming to land carbon cycle processes. Environmental Research Letters 7, 024002 (2012).

4. K.-H. Erb et al., Unexpectedly large impact of forest management and grazing on global vegetation biomass. Nature 553, 73 (2017).

5. W. Wang et al., Variations in atmospheric $\mathrm{CO}_{2}$ growth rates coupled with tropical temperature. Proceedings of the National Academy of Sciences 110, 13061 (2013).

6. J. Liu et al., Contrasting carbon cycle responses of the tropical continents to the 2015-2016 El Niño. Science 358, eaam5690 (2017).

7. D. A. Clark, S. C. Piper, C. D. Keeling, D. B. Clark, Tropical rain forest tree growth and atmospheric carbon dynamics linked to interannual temperature variation during 19842000. Proceedings of the National Academy of Sciences 100, 5852 (2003).

8. W. R. L. Anderegg et al., Tropical nighttime warming as a dominant driver of variability in the terrestrial carbon sink. Proceedings of the National Academy of Sciences 112, 15591-15596 (2015).

9. A. Ballantyne et al., Accelerating net terrestrial carbon uptake during the warming hiatus due to reduced respiration. Nature Climate Change 7, 148 (2017).

10. J. K. Green et al., Large influence of soil moisture on long-term terrestrial carbon uptake. Nature 565, 476-479 (2019).

11. O. L. Phillips et al., Drought Sensitivity of the Amazon Rainforest. Science 323, 1344 (2009). 
Sullivan et al. Thermal sensitivity of tropical forests

12. M. D. Smith, A. K. Knapp, S. L. Collins, A framework for assessing ecosystem dynamics in response to chronic resource alterations induced by global change. Ecology 90, 3279-3289 (2009).

13. J. H. Brown, T. J. Valone, C. G. Curtin, Reorganization of an arid ecosystem in response to recent climate change. Proceedings of the National Academy of Sciences 94, 9729-9733 (1997).

14. S. Fauset et al., Drought-induced shifts in the floristic and functional composition of tropical forests in Ghana. Ecology Letters 15, 1120-1129 (2012).

15. A. Gunderson Carla, H. O'Hara Keiran, M. Campion Christina, V. Walker Ashley, T. Edwards Nelson, Thermal plasticity of photosynthesis: the role of acclimation in forest responses to a warming climate. Global Change Biology 16, 2272-2286 (2010).

16. M. Slot et al., Thermal acclimation of leaf respiration of tropical trees and lianas: response to experimental canopy warming, and consequences for tropical forest carbon balance. Global Change Biology 20, 2915-2926 (2014).

17. F. Ow Lai, L. Griffin Kevin, D. Whitehead, S. Walcroft Adrian, H. Turnbull Matthew, Thermal acclimation of leaf respiration but not photosynthesis in Populus deltoides×nigra. New Phytologist 178, 123-134 (2008).

18. T. F. Domingues et al., Ecophysiological plasticity of Amazonian trees to long-term drought. Oecologia 187, 933-940 (2018).

19. See suplimentary materials.

20. J. W. F. Slik et al., Phylogenetic classification of the world's tropical forests. Proceedings of the National Academy of Sciences 115, 1837 (2018).

21. S. Dray, P. Legendre, P. R. Peres-Neto, Spatial modelling: a comprehensive framework for principal coordinate analysis of neighbour matrices (PCNM). Ecological Modelling 196, 483493 (2006).

22. L. Breiman, Random Forests. Machine Learning 45, 5-32 (2001). 
Sullivan et al. Thermal sensitivity of tropical forests

23. N. McDowell et al., Drivers and mechanisms of tree mortality in moist tropical forests. New Phytologist 219, 851-869 (2018).

24. G. Fontes Clarissa et al., Dry and hot: the hydraulic consequences of a climate change-type drought for Amazonian trees. Philosophical Transactions of the Royal Society B: Biological Sciences 373, 20180209 (2018).

25. P. Ciais et al., Europe-wide reduction in primary productivity caused by the heat and drought in 2003. Nature 437, 529-533 (2005).

26. M. E. Dusenge, A. G. Duarte, D. A. Way, Plant carbon metabolism and climate change: elevated $\mathrm{CO} 2$ and temperature impacts on photosynthesis, photorespiration and respiration. New Phytologist 221, 32-49 (2019).

27. S. Pau, M. Detto, Y. Kim, C. J. Still, Tropical forest temperature thresholds for gross primary productivity. Ecosphere 9, e02311 (2018).

28. D. A. Clark, D. B. Clark, S. F. Oberbauer, Field-quantified responses of tropical rainforest aboveground productivity to increasing CO2 and climatic stress, 1997-2009. Journal of Geophyical Research - Biogeosciences. 118, 783-794 (2013).

29. W. R. L. Anderegg et al., Hydraulic diversity of forests regulates ecosystem resilience during drought. Nature 561, 538-541 (2018).

30. V. Avitabile et al., An integrated pan-tropical biomass map using multiple reference datasets. Global Change Biology 22, 1406-1420 (2016).

31. S. E. Fick, R. J. Hijmans, WorldClim 2: new 1-km spatial resolution climate surfaces for global land areas. International Journal of Climatology 37, 4302-4315 (2017).

32. S. Piao et al., Evaluation of terrestrial carbon cycle models for their response to climate variability and to CO2 trends. Global Change Biology 19, 2117-2132 (2013).

33. L. M. Mercado et al., Large sensitivity in land carbon storage due to geographical and temporal variation in the thermal response of photosynthetic capacity. New Phytologist 218, 1462-1477 (2018). 
Sullivan et al. Thermal sensitivity of tropical forests

Additional references cited in suplementary materials

34. A. B. Anderson, White-sand vegetation of Brazilian Amazonia. Biotropica 13, 199-210 (1981).

35. S. R. Pezeshki, Root responses of flood-tolerant and flood-sensitive tree species to soil redox conditions. Trees 5, 180-186 (1991).

36. O. L. Phillips, T. R. Baker, T. R. Feldpausch, R. J. W. Brienen, RAINFOR Field Manual for Plot Establishment and Remeasurement (University of Leeds, 2001).

37. J. Talbot et al., Methods to estimate aboveground wood productivity from long-term forest inventory plots. Forest Ecology and Management 320, 30-38 (2014).

38. D. B. Clark, D. A. Clark, Landscape-scale variation in forest structure and biomass in a tropical rain forest. Forest Ecology and Management 137, 185-198 (2000).

39. G. Lopez-Gonzalez, S. L. Lewis, M. Burkitt, O. L. Phillips, ForestPlots.net: a web application and research tool to manage and analyse tropical forest plot data. Journal of Vegetation Science 22, 610-613 (2011).

40. G. Lopez-Gonzalez, S. L. Lewis, M. Burkitt, T. R. Baker, O. L. Phillips, ForestPlots.net Database. www.forestplots.net. (2009).

41. R. J. W. Brienen et al., Long-term decline of the Amazon carbon sink. Nature 519, 344-348 (2015).

42. J. Chave et al., Improved allometric models to estimate the aboveground biomass of tropical trees. Global Change Biology 20, 3177-3190 (2014).

43. J. Chave et al., Towards a worldwide wood economics spectrum. Ecology Letters 12, 351-366 (2009).

44. A. E. Zanne et al. Data from: Towards a worldwide wood economics spectrum. https://datadryad.org/stash/dataset/doi:10.5061/dryad.234 (Dryad Data Repository, 2009).

45. R. C. Goodman et al., Amazon palm biomass and allometry. Forest Ecology and Management 310, 994-1004 (2013). 
Sullivan et al. Thermal sensitivity of tropical forests

46. M. J. P. Sullivan et al., Field methods for sampling tree height for tropical forest biomass estimation. Methods in Ecology and Evolution 9, 1179-1189 (2018).

47. S. C. Thomas, Asymptotic height as a predictor of growth and allometric characteristics in malaysian rain forest trees. American Journal of Botany 83, 556-566 (1996).

48. T. R. Feldpausch et al., Tree height integrated into pantropical forest biomass estimates. Biogeosciences 9, 3381-3403 (2012).

49. T. S. Kohyama, T. I. Kohyama, D. Sheil, Definition and estimation of vital rates from repeated censuses: Choices, comparisons and bias corrections focusing on trees. Methods in Ecology and Evolution 9, 809-821 (2018).

50. A. R. Martin, M. Doraisami, S. C. Thomas, Global patterns in wood carbon concentration across the world's trees and forests. Nature Geoscience 11, 915-920 (2018).

51. D. Galbraith et al., Residence times of woody biomass in tropical forests. Plant Ecology \& Diversity 6, 139-157 (2013).

52. G. Lopez-Gonzalez, M. J. P. Sullivan, T. R. Baker. BiomasaFP: R package for analysing data downloaded from ForestPlots.net (2015).

53. R. J. Hijmans, S. Phillips, J. Leathwick, J. Elith, dismo: Species distribution modeling. R package version 1.0-12. (2015).

54. A. M. Wilson, W. Jetz, Remotely Sensed High-Resolution Global Cloud Dynamics for Predicting Ecosystem and Biodiversity Distributions. PLOS Biology 14, e1002415 (2016).

55. M. New, D. Lister, M. Hulme, I. Makin, A high-resolution data set of surface climate over global land areas. Climate Research 21, 1-25 (2002).

56. T. Hengl et al., SoilGrids250m: Global gridded soil information based on machine learning. PLOS ONE 12, e0169748 (2017).

57. P. R. Peres-Neto, P. Legendre, Estimating and controlling for spatial structure in the study of ecological communities. Global Ecology and Biogeography 19, 174-184 (2010). 
Sullivan et al. Thermal sensitivity of tropical forests

58. S. L. Lewis et al., Increasing carbon storage in intact African tropical forests. Nature 457, 1003 (2009).

59. K. Barton, MuMIn: Multi-Model Inference. R package version 1.12.1. http://CRAN.Rproject.org/package=MuMIn (2015).

60. V. M. R. Muggeo, Estimating regression models with unknown break-points. Statistics in Medicine 22, 3055-3071 (2003).

61. A. Liaw, M. Wiener, Classificiation and Regression by randomForest. $R$ News 2, 18-22 (2002).

62. D. M. Olson et al., Terrestrial Ecoregions of the World: A New Map of Life on EarthA new global map of terrestrial ecoregions provides an innovative tool for conserving biodiversity. BioScience 51, 933-938 (2001).

63. M. C. Hansen et al., High-Resolution Global Maps of 21st-Century Forest Cover Change. Science 342, 850-853 (2013).

64. R. Jackson et al., A global analysis of root distributions for terrestrial biomes. Oecologia 108, 389-411 (1996).

65. S. S. Saatchi et al., Benchmark map of forest carbon stocks in tropical regions across three continents. Proceedings of the National Academy of Sciences 108, 9899-9904 (2011).

66. A. Baccini et al., Estimated carbon dioxide emissions from tropical deforestation improved by carbon-density maps. Nature Climate Change 2, 182-185 (2012).

67. E. T. A. Mitchard et al., Uncertainty in the spatial distribution of tropical forest biomass: a comparison of pan-tropical maps. Carbon Balance and Management 8, 10 (2013).

68. E. T. Mitchard et al., Markedly divergent estimates of A mazon forest carbon density from ground plots and satellites. Global Ecology and Biogeography 23, 935-946 (2014).

69. R. J. Hijmans. WorldClim Future Climate Data https://www.worldclim.org/cmip5v1. (2005).

70. R. J. Hijmans, S. E. Cameron, J. L. Parra, P. G. Jones, A. Jarvis, Very high resolution interpolated climate surfaces for global land areas. International Journal of Climatology 25, 1965-1978 (2005). 
Sullivan et al. Thermal sensitivity of tropical forests

71. B. Kirtman et al., Near-term climate change: projections and predictability. (2013).

72. H. D. Matthews, K. Caldeira, Stabilizing climate requires near-zero emissions. Geophysical Research Letters 35, (2008).

73. M. Meinshausen et al., The RCP greenhouse gas concentrations and their extensions from 1765 to 2300. Climatic Change 109, 213 (2011).

74. W. Kolby Smith et al., Large divergence of satellite and Earth system model estimates of global terrestrial CO2 fertilization. Nature Climate Change 6, 306 (2015).

75. D. W. Kicklighter et al., A first-order analysis of the potential role of $\mathrm{CO} 2$ fertilization to affect the global carbon budget: a comparison of four terrestrial biosphere models. Tellus $B$ : Chemical and Physical Meteorology 51, 343-366 (1999).

76. Y. Malhi et al., The linkages between photosynthesis, productivity, growth and biomass in lowland Amazonian forests. Global Change Biology 21, 2283-2295 (2015).

77. C. Terrer et al., Nitrogen and phosphorus constrain the $\mathrm{CO} 2$ fertilization of global plant biomass. Nature Climate Change 9, 684-689 (2019).

78. E. Bartholome, A. S. Belward, GLC2000: a new approach to global land cover mapping from Earth observation data. International Journal of Remote Sensing 26, 1959-1977 (2005).

79. J. Chave et al., Tree allometry and improved estimation of carbon stocks and balance in tropical forests. Oecologia 145, 87-99 (2005).

80. M. Slot, K. Winter, In situ temperature response of photosynthesis of 42 tree and liana species in the canopy of two Panamanian lowland tropical forests with contrasting rainfall regimes. New Phytologist 214, 1103-1117 (2017).

81. Y. Malhi, The productivity, metabolism and carbon cycle of tropical forest vegetation. Journal of Ecology 100, 65-75 (2012).

82. E. A. Graham, S. S. Mulkey, K. Kitajima, N. G. Phillips, S. J. Wright, Cloud cover limits net CO2 uptake and growth of a rainforest tree during tropical rainy seasons. Proceedings of the National Academy of Sciences 100, 572-576 (2003). 
Sullivan et al. Thermal sensitivity of tropical forests

83. W. F. Laurance, T. J. Curran, Impacts of wind disturbance on fragmented tropical forests: A review and synthesis. Austral Ecology 33, 399-408 (2008).

347

Acknowledgements: This paper is a product of the RAINFOR, AfriTRON and T-FORCES networks, and is facilitated by ForestPlots.net technology for data management which promotes science synergies across countries and continents. While these initiatives have been supported by numerous people and grants since their inception we are particularly indebted to hundreds of institutions, field assistants and local communities for help in establishing and maintaining the plots. For additional assistance with access to datasets we thank Jon Lloyd, Carlos Quesada, Michel Baisie, Olaf Banki, Wemo Betian, Vincent Bezard, Rene Boot, Mireille Breuer-Ndoundou Hockemba, Ezequiel Chavez, Douglas Daly, Armandu Daniels, Darcy Galiano Cabrera, Toby Gardner, Paolo Graca, Andrew Graham, Olivier Hardy, Eduardo Hase, David Hilvert, Muhammad Idhamsyah, Phillipe Jeanmart, Cisquet Keibou Opepa, Jeanette Kemp, Wilmar Lopez Oviedo, Jean-Remy Makana, Faustin Mbaya Mpanya Lukasu, Irina Mendoza Polo, Edi Mirmanto, Sam Moore, Jacques Mukinzi, Pétrus Naisso, Lucas Ojo, Raimunda Oliveira de Araújo, Sonia Cesarina Palacios Ramos, Alexander Parada Gutierrez, Guido Pardo, Marielos Peña-Claros, Freddy Ramirez Arevalo, Antonio Lima, Rodrigo Sierra, Natalino Silva, Marc Steininger, Marisol Toledo, John Tshibamba Mukendi, Darlington Tuagben, Hannsjoerg Woell and Ishak Yassir. We thank Jon Lloyd, Carlos Quesada for discussions and three anonymous reviewers for helpful comments and suggestions. Funding: The networks have been supported by multiple grants, most notably the European Research Council (ERC Advanced Grant 291585 - 'T-FORCES'), the Gordon and Betty Moore Foundation (\#1656 'RAINFOR' and Monitoring Protected Areas in Peru to Increase Forest Resilience to Climate Change), the David and Lucile Packard Foundation, the European Union's Seventh Framework Programme (283080 'GEOCARBON', 282664 - 'AMAZALERT'), the Natural Environment Research Council (NERC grants NE/D005590/1 - 'TROBIT', NE/F005806/1 - 'AMAZONICA', NERC Urgency Grants and a NERC New Investigators Grant), the NERC/ State of São Paulo Research Foundation (FAPESP) consortium grants 'BIO-RED' (NE/N012542/1, 2012/51872-5) and 'ECOFOR' (NE/K016431/1, 2012/51509-8), the Royal Society, the Centre for International Forestry (CIFOR) and Gabon's National Parks Agency (ANPN). Additional data were included from the Tropical Ecology Assessment and Monitoring (TEAM) Network, a collaboration between Conservation International, the Missouri Botanical Garden, the Smithsonian Institution and the Wildlife Conservation Society, and partly funded by these institutions, the Gordon and Betty Moore Foundation, and other donors. M.J.P.S. was supported by the ERC (T-FORCES), NERC ('BIO-RED') and the Royal Society (CH160091), S.L.L. by a Royal Society University Research Fellowship, ERC Advanced Grant and a Phillip Leverhulme Prize, and O.L.P. by an ERC Advanced Grant and a Royal Society Wolfson Research Merit Award. We thank the National Council for Science and Technology Development of Brazil (CNPq) for support to the Cerrado/Amazonia Transition Long-Term Ecology Project (PELD/403725/2012-7), the PPBio Phytogeography of Amazonia/Cerrado Transition project (CNPq/PPBio/457602/2012-0) and a Productivity Grant to B.S.M. and B.H.M-J.. Funding for plots in the Udzungwa Mountains (Tanzania) was obtained from the Leverhulme Trust under the Valuing the Arc project. This study is contribution number XXX to the Technical Series (TS) of the BDFFP (INPA - STRI). Data from RAINFOR, AfriTRON and T-FORCES are stored and curated by ForestPlots.net, a cyber-infrastructure initiative hosted at the University of Leeds that unites permanent plot records and their contributing scientists from the world's tropical forests. The development of ForestPlots.net and curation of most data analysed here was funded by several grants to O.L.P. (principally from NERC NE/B503384/1, NE/N012542/1 BIO-RED, ERC AdG 291585 TFORCES', and Gordon and Betty Moore Foundation \#1656, 'RAINFOR'), E.G. ('GEOCARBON', and NE/F005806/1 'AMAZONICA'), T.R.B. (Gordon and Betty Moore Foundation 'Monitoring Protected Areas in Peru to Increase Forest Resilience to Climate Change'), S.L.L. (Royal Society 
University Research Fellowship; NERC New Investigators Award; Phillip Leverhulme Prize), and D.G. (NERC NE/N004655/1, 'TREMOR'). Author contributions: O.L.P., S.L.L. and Y.M. conceived the RAINFOR, AfriTRON and T-FORCES forest census network programmes; M.J.P.S., S.L.L. and O.L.P. conceived and designed the study. L.A., A.A.-M., T.R.B., R.J.W.B., S.K.B., K.AB., F.C., C.C., E.A.D., A.C.S., C.E.N.E., T.R.F., W.H., S.L.L., A.M.M., B.S.M., O.L.P., L.Q., B.S., T.S., R.V. and L.J.T.W. coordinated data collection with the help of most co-authors. O.L.P., T.R.B., G.L.-G. and S.L.L. conceived and managed ForestPlots.net; O.L.P., T.R.B., D.G., E.G. and S.L.L. funded it, and R.B., T.F., G.L.-G., A.L., G.C.P. and M.J.P.S. helped develop it. M.J.P.S., T.R.B., W.H., S.L.L., A.E.-M., and L.Q. contributed tools to analyse data. All authors collected or supported the collection of field data, M.J.P.S. analysed the data, M.J.P.S., S.L.L. and O.L.P. wrote the manuscript with contributions from other authors. All co-authors commented on or approved the manuscript. Competing interests: The authors declare no competing financial interests. Data and materials availability: Plot-level input data and $\mathrm{R}$ scripts will be deposited as a data package on ForestPlots.net (doi-xxx). 
Sullivan et al. Thermal sensitivity of tropical forests

408 Supplementary Materials:

409 Materials and Methods

410 Figures S1-S15

411 Tables S1-S3

412 References (34-83) 
413

A

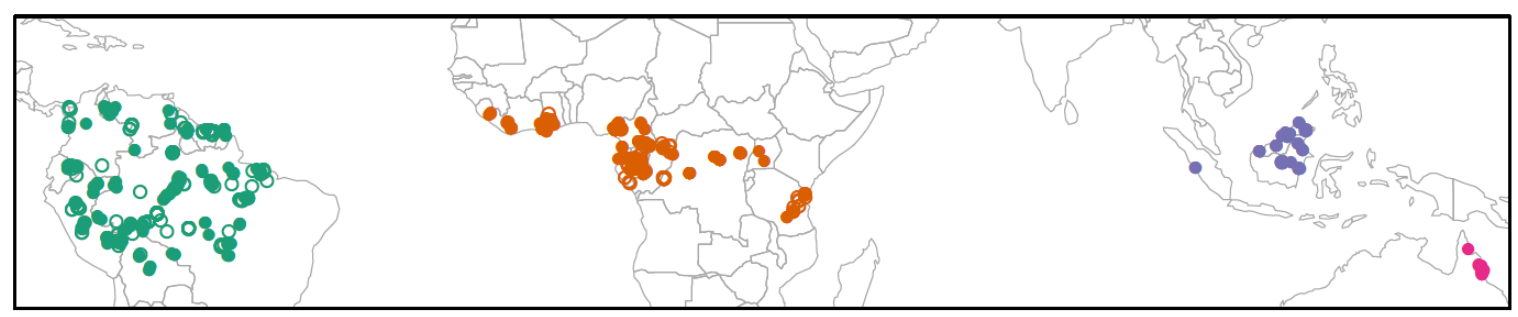

B

[Different letters in brackets indicate statistically significant differences accounting for environmental variables]

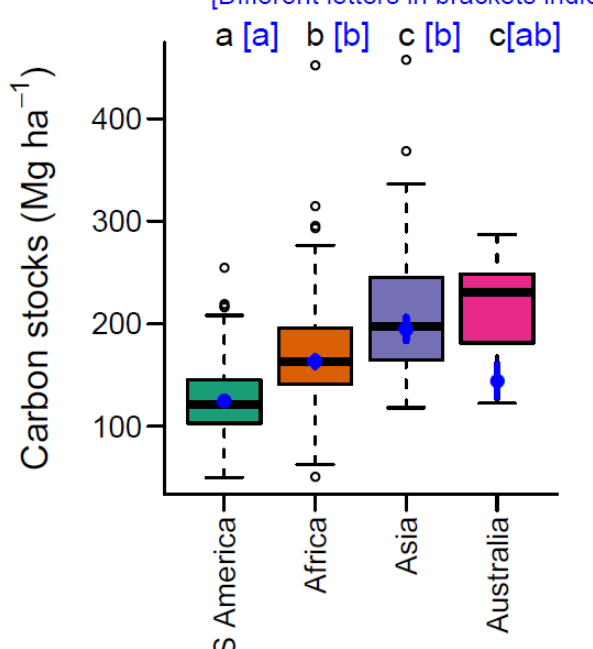

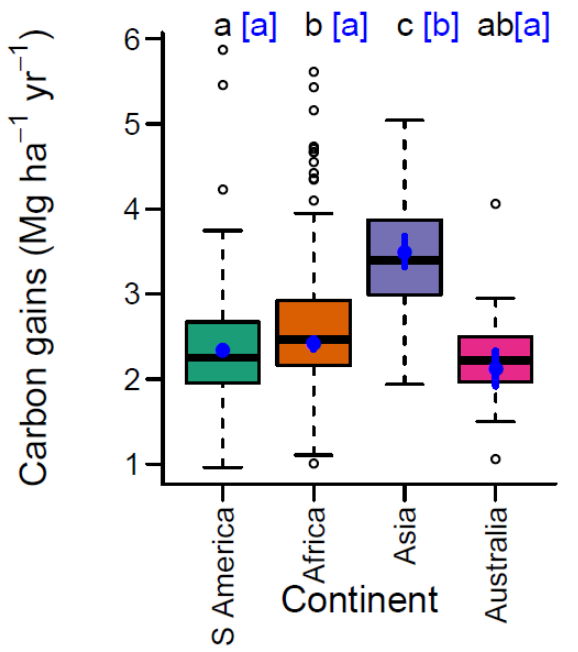

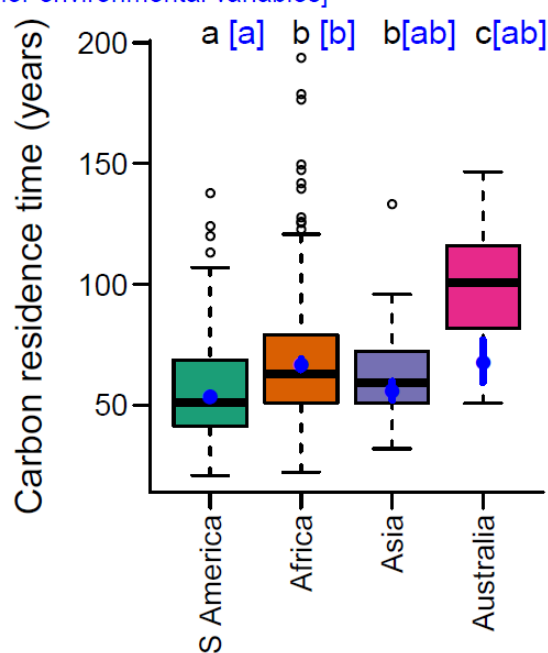

Figure 1. Spatial variation in tropical forest carbon. (A) Our plot network. Filled symbols show multi-census plots used in the main analysis, open symbols 

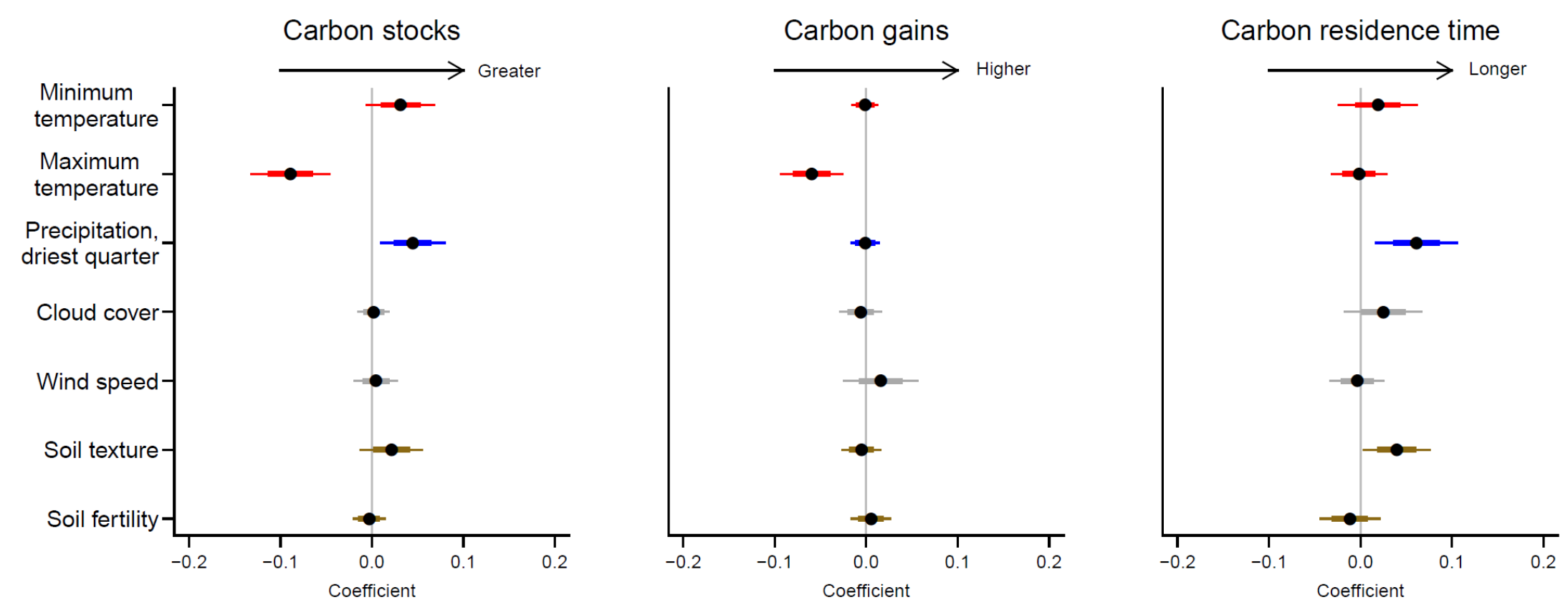

Figure 2. Correlates of spatial variation in tropical forest carbon. Points show coefficients from model-averaged general linear models. Variables that did not occur in well-supported models are shrinkage adjusted towards zero. Coefficients are standardised so that they represent change in the response variable for one standard deviation change in the explanatory variable. Error bars show standard errors (thick lines) and 95\% confidence intervals (thin lines). Soil texture is represented by the percentage clay, and soil fertility by cation exchange capacity. The full models explained $44.1 \%, 31.4 \%$ and $30.9 \%$ of spatial variation 


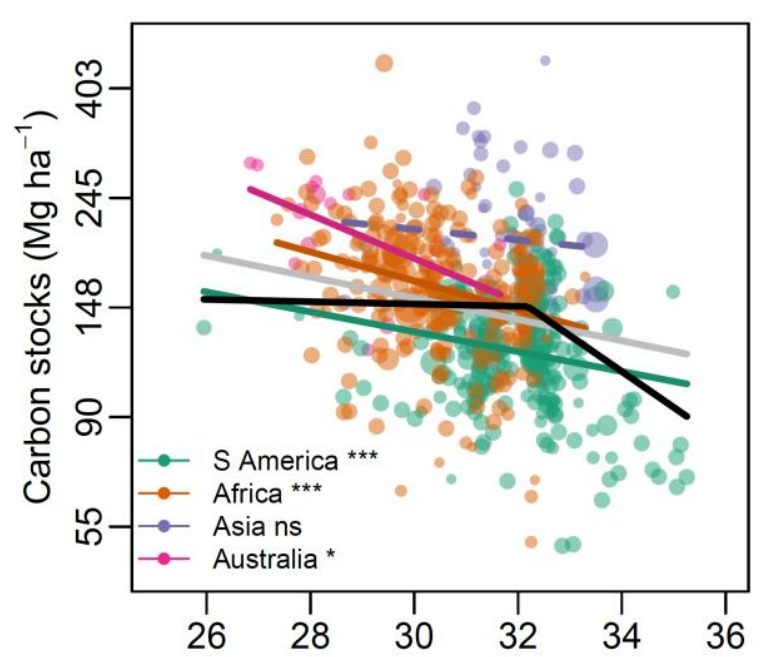

Mean daily maximum temperature in the warmest month $\left({ }^{\circ} \mathrm{C}\right)$

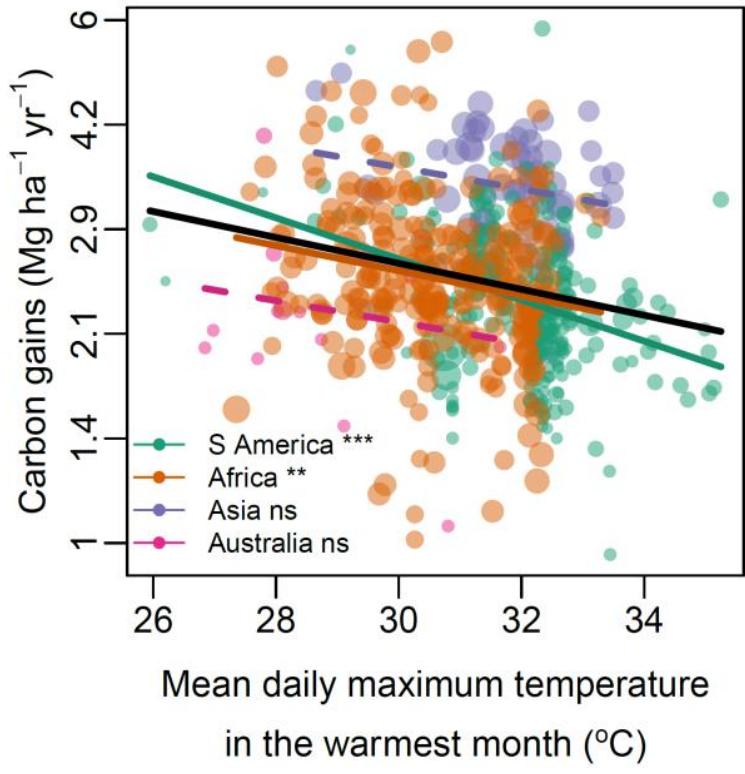

in the warmest month $\left({ }^{\circ} \mathrm{C}\right)$

Figure 3. Temperature effects on tropical forest carbon stocks (left) and carbon gains from woody productivity (right). Black lines show the best pan-tropical relationships accounting for environmental covariates. The grey line shows the additional linear pan-tropical relationship for carbon stocks.

434 Coloured lines show bivariate relationships within each continent. Statistically significant relationships are shown with solid lines, non-significant with dashed lines. Symbol point size is proportional to weights used in model fitting based on plot size and monitoring length, see SI Materials and Methods. Linear and break-point pan-tropical relationships are all statistically significant $(P<0.001)$, as are better sampled continents. Relationships with other variables are shown in Fig. S8-S10. *** $P<0.001, * * P<0.01, * P<0.05$, ns $P \geq 0.05$. 
$\Delta$ Carbon stocks $\left(\mathrm{Mg} \mathrm{ha}^{-1}\right)$

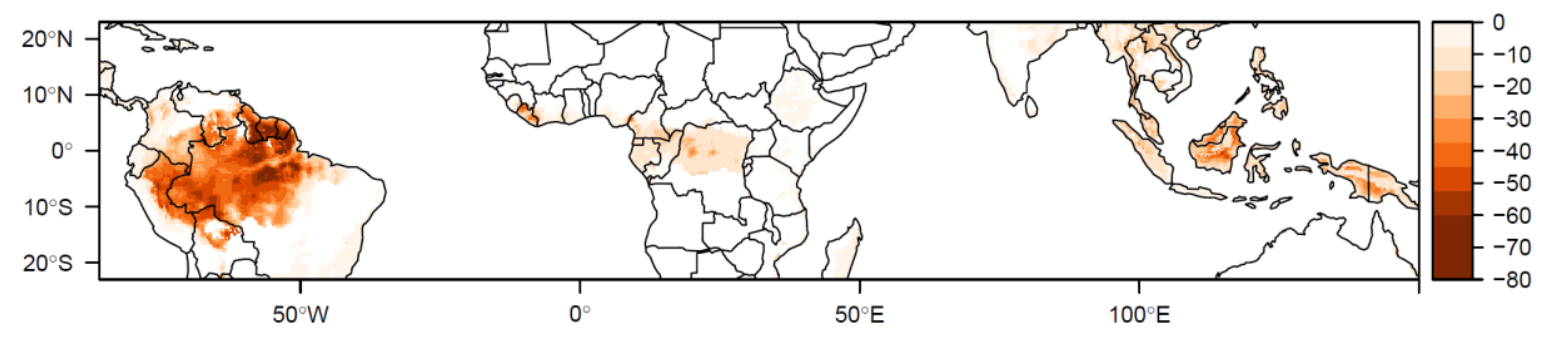

$\Delta$ Carbon stocks (\%)

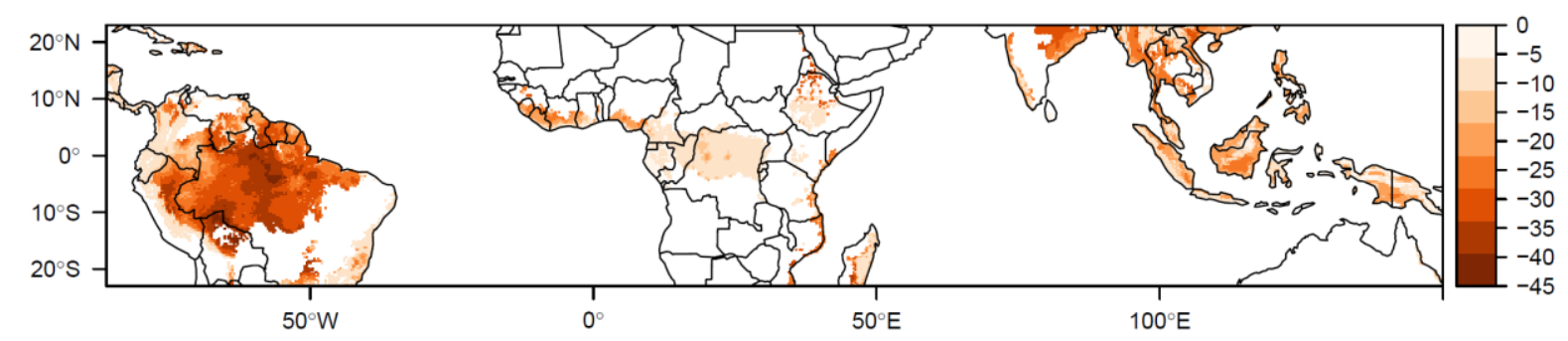

442

Figure 4. Long-term change in carbon stocks due to global surface temperature warming of

approximately $2^{\circ} \mathrm{C}$. Future temperatures come from an ensemble of 15 climate models for RCP4.5,

2040-2060, which give global mean surface temperatures $\sim 1.9^{\circ} \mathrm{C}$ above pre-industrial. Maps show

the predicted absolute and relative change in tropical forest carbon stocks if global temperatures baseline climate. Note parts of the biome become warmer than currently observed in our dataset (Fig.

S13). See Fig. S14 for predictions using alternative carbon reference maps. Predictions are based on temperature alone and do not include precipitation changes (for which future patterns of change are uncertain) or potential moderation via elevated $\mathrm{CO}_{2}$ (see Fig. S15). 
Supporting information for Sullivan et al.

\section{Supporting information for Long-term thermal Sensitivity of the Earth's Tropical Forests}

Martin J. P. Sullivan ${ }^{1,2}$, Simon L. Lewis ${ }^{1,3}$, Kofi Affum-Baffoe ${ }^{4}$, Carolina Castilho ${ }^{5}$, Flávia Costa $^{6}$, Aida Cuni Sanchez ${ }^{7,8}$, Corneille E. N. Ewango $9,10,11$, Wannes Hubau ${ }^{1,12,13}$, Beatriz Marimon ${ }^{14}$, Abel MonteagudoMendoza $^{15}$, Lan Qie ${ }^{16}$, Bonaventure Sonké ${ }^{17}$, Rodolfo Vasquez Martinez ${ }^{15}$, Timothy R Baker ${ }^{1}$, Roel J. W. Brienen $^{1}$, Ted R. Feldpausch ${ }^{18}$, David Galbraith ${ }^{1}$, Manuel Gloor ${ }^{1}$, Yadvinder Malhi ${ }^{19}$, Shin-Ichiro Aiba ${ }^{20}$, Miguel N. Alexiades ${ }^{21}$, Everton C. Almeida ${ }^{22}$, Edmar Almeida de Oliveira ${ }^{23}$, Esteban Álvarez Dávila ${ }^{24}$, Patricia Alvarez Loayza ${ }^{25}$, Ana Andrade ${ }^{26}$, Simone Aparecida Vieira ${ }^{27}$, Luiz Aragão ${ }^{28}$, Alejandro AraujoMurakami $^{29}$, Eric J.M.M. Arets ${ }^{30}$, Luzmila Arroyo ${ }^{31}$, Peter Ashton ${ }^{32}$, Gerardo Aymard C. ${ }^{33}$, Fabrício B. Baccaro $^{34}$, Lindsay F. Banin ${ }^{35}$, Christopher Baraloto ${ }^{36}$, Plínio Barbosa Camargo ${ }^{37}$, Jos Barlow ${ }^{38}$, Jorcely Barroso $^{39}$, Jean-François Bastin ${ }^{40}$, Sarah A. Batterman ${ }^{1,41,42,43}$, Hans Beeckman ${ }^{12}$, Serge K. Begne ${ }^{17,44}$, Amy C. Bennett ${ }^{44}$, Erika Berenguer ${ }^{19,38}$, Nicholas Berry ${ }^{45}$, Lilian Blanc ${ }^{46}$, Pascal Boeckx ${ }^{47}$, Jan Bogaert ${ }^{48}$, Damien Bonal $^{49}$, Frans Bongers ${ }^{50}$, Matt Bradford ${ }^{51}$, Francis Q. Brearley ${ }^{2}$, Terry Brncic ${ }^{52}$, Foster Brown ${ }^{53}$, Benoit Burban $^{54}$, José Luís Camargo ${ }^{26}$, Wendeson Castro ${ }^{55}$, Carlos Céron ${ }^{56}$, Sabina Cerruto Ribeiro ${ }^{57}$, Victor Chama Moscoso ${ }^{15}$, Jerôme Chave ${ }^{58}$, Eric Chezeaux ${ }^{59}$, Connie J. Clark ${ }^{25}$, Fernanda Coelho ${ }^{1}$, Murray Collins $^{61}$, James A. Comiskey ${ }^{62,63}$, Fernando Cornejo Valverde ${ }^{64}$, Massiel Corrales Medina ${ }^{65}$, Lola da Costa $^{66}$, Martin Dančák ${ }^{67}$, Greta C. Dargie ${ }^{1}$, Stuart Davies ${ }^{68}$, Nallaret Davila Cardozo ${ }^{69}$, Thales de Haulleville ${ }^{12,48}$, Marcelo Brilhante de Medeiros ${ }^{70}$, Jhon del Aguila Pasquel ${ }^{71}$, Géraldine Derroire ${ }^{72}$, Anthony Di Fiore $^{73}$, Jean-Louis Doucet ${ }^{74}$, Aurélie Dourdain ${ }^{72}$, Vincent Droissant ${ }^{75}$, Luisa Fernanda Duque ${ }^{76}$, Romeo Ekoungoulou $^{77}$, Fernando Elias ${ }^{78}$, Terry Erwin ${ }^{79}$, Adriane Esquivel-Muelbert ${ }^{80}$, Sophie Fauset ${ }^{81}$, Joice Ferreira $^{82}$, Gerardo Flores Llampazo ${ }^{83}$, Ernest Foli ${ }^{84}$, Andrew Ford ${ }^{51}$, Martin Gilpin ${ }^{1}$, Jefferson S. Hall ${ }^{85}$, Keith C. Hamer ${ }^{86}$, Alan C. Hamilton ${ }^{87}$, David J. Harris ${ }^{88}$, Terese B. Hart ${ }^{89,90}$, Radim Hédl ${ }^{91,92}$, Bruno Herault $^{72}$, Rafael Herrera ${ }^{93}$, Niro Higuchi ${ }^{6}$, Annette Hladik ${ }^{94}$, Eurídice Honorio Coronado ${ }^{71}$, Isau Huamantupa-Chuquimaco ${ }^{95}$, Walter Huaraca Huasco ${ }^{95}$, Kathryn J. Jeffery ${ }^{96}$, Eliana Jimenez-Rojas ${ }^{97}$, Michelle Kalamandeen ${ }^{1}$, Marie-Noel Kamdem ${ }^{11,13,17,98}$, Elizabeth Kearsley ${ }^{99}$, Ricardo Keichi Umetsu ${ }^{100}$, Lip Khoon Kho Khoon ${ }^{101}$, Timothy Killeen ${ }^{102}$, Kanehiro Kitayama ${ }^{103}$, Bente Klitgaard ${ }^{104}$, Nicolas Labrière ${ }^{58}$, William Laurance ${ }^{105}$, Susan Laurance ${ }^{105}$, Miguel E. Leal ${ }^{106}$, Aurora Levesley ${ }^{1}$, Adriano J. N. Lima ${ }^{6}$, Janvier Lisingo $^{11}$, Aline P. Lopes ${ }^{107,108}$, Gabriela Lopez-Gonzalez ${ }^{1}$, Tom Lovejoy ${ }^{109}$, Jon Lovett ${ }^{1}$, Richard Lowe ${ }^{110}$, William E. Magnusson ${ }^{111}$, Jagoba Malumbres-Olarte ${ }^{12,113}$, Ângelo Gilberto Manzatto ${ }^{114}$, Ben Hur Marimon Junior ${ }^{115}$, Andrew R. Marshall ${ }^{8,116,117}$, Toby Marthews ${ }^{118}$, Simone Matias de Almeida Reis ${ }^{14,19}$, Colin Maycock $^{119}$, Karina Melgaço ${ }^{1}$, Casimiro Mendoza ${ }^{120}$, Faizah Metali ${ }^{121}$, Vianet Mihindou ${ }^{122,123}$, William Milliken ${ }^{104}$, Edward Mitchard ${ }^{124}$, Paulo S. Morandi ${ }^{14}$, Hannah L. Mossman ${ }^{2}$, Laszlo Nagy ${ }^{125}$, Henrique Nascimento $^{6}$, David Neill ${ }^{126}$, Reuben Nilus ${ }^{127}$, Percy Núñez Vargas ${ }^{95}$, Walter Palacios ${ }^{128}$, Nadir Pallqui Camacho $^{1,95}$, Julie Peacock ${ }^{1}$, Colin Pendry ${ }^{129}$, Maria Cristina Peñuela Mora ${ }^{130}$, Georgia C. Pickavance ${ }^{1}$, John Pipoly ${ }^{131}$, Nigel Pitman ${ }^{132}$, Maureen Playfair ${ }^{133}$, Lourens Poorter ${ }^{134}$, John R. Poulsen ${ }^{25}$, Axel D. Poulsen ${ }^{135}$, Richard Preziosi ${ }^{2}$, Adriana Prieto ${ }^{136}$, Richard Primack ${ }^{137}$, Hirma Ramírez-Angulo ${ }^{138}$, Jan Reitsma ${ }^{139}$, Maxime Réjou-Méchain ${ }^{75}$, Zorayda Restrepo Correa ${ }^{140}$, Thaiane Rodrigues de Sousa ${ }^{6}$, Lily Rodriguez Bayona $^{141}$, Anand Roopsind ${ }^{142}$, Agustín Rudas ${ }^{136}$, Ervan Rutishauser ${ }^{42,143}$, Kamariah Abu Salim ${ }^{121}$, Rafael P. Salomão ${ }^{144,145}$, Juliana Schietti ${ }^{6}$, Douglas Sheil ${ }^{146}$, Richarlly C. Silva ${ }^{57,147}$, Javier Silva Espejo ${ }^{148}$, Camila Silva Valeria ${ }^{38}$, Marcos Silveira ${ }^{57}$, Murielle Simo-Droissart ${ }^{17}$, Marcelo Fragomeni Simon ${ }^{70}$, James Singh ${ }^{149}$, Yahn Carlos Soto Shareva ${ }^{15}$, Clement Stahl ${ }^{54}$, Juliana Stropp ${ }^{150}$, Rahayu Sukri ${ }^{121}$, Terry Sunderland ${ }^{151,152}$, Martin Svátek ${ }^{153}$, Michael D. Swaine ${ }^{154}$, Varun Swamy ${ }^{155}$, Hermann Taedoumg ${ }^{17}$, Joey Talbot ${ }^{1}$, James Taplin $^{156}$, David Taylor ${ }^{157}$, Hans ter Steege ${ }^{158,159}$, John Terborgh ${ }^{25}$, Raquel Thomas ${ }^{142}$, Sean C. Thomas ${ }^{160}$, Armando Torres-Lezama ${ }^{161}$, Peter Umunay ${ }^{162,163}$, Luis Valenzuela Gamarra ${ }^{15}$, Geertje van der Heijden ${ }^{164}$, Peter van der Hout ${ }^{165}$, Peter van der Meer ${ }^{166}$, Mark van Nieuwstadt ${ }^{167}$, Hans Verbeeck ${ }^{99}$, Ronald Vernimmen $^{168}$, Alberto Vicentini ${ }^{6}$, Ima Célia Guimarães Vieira ${ }^{145}$, Emilio Vilanova Torre ${ }^{169}$, Jason Vleminckx ${ }^{36}$, Vincent $\operatorname{Vos}^{171}$, Ophelia Wang ${ }^{172}$, Lee J. T. White ${ }^{123,173,174}$, Simon Willcock ${ }^{175}$, John T. Woods $^{176}$, Verginia Wortel ${ }^{177}$, Kenneth Young ${ }^{178}$, Roderick Zagt ${ }^{179}$, Lise Zemagho ${ }^{17}$, Pieter A. Zuidema ${ }^{50}$, Joeri A. Zwerts ${ }^{177,180}$, Oliver L. Phillips ${ }^{1}$ 
Supporting information for Sullivan et al.

505 This file includes:

506 Materials and Methods

507 Figures S1 - S15

508 Tables S1 - S3

509 
Supporting information for Sullivan et al.

\section{$510 \quad$ Materials and Methods}

\section{$511 \quad$ Forest census data}

512 Our plots come from the RAINFOR, AfriTRON, and T-FORCES networks. Forest inventory plots were located in lowland $(<1200 \mathrm{~m})$, old-growth, closed-canopy forests that were not known to have

514 been subject to anthropogenic disturbance through fire or selective logging. Plots characterised

515 floristically as dry forest were not included, as were plots that received less than $1200 \mathrm{~mm}$

516 precipitation each year. We also did not include plots in white sand, swamp and seasonally flooded

517 forests, as we expect these to experience marked edaphic constraints (extreme nutrient limitation for 518 white sand forests (34), stress caused by hypoxic conditions for swamp and seasonally flooded forests 519 (35)). All plots were $\geq 0.2$ ha (median size $=1$ ha) and were monitored for at least two years (median 520 monitoring period $=9.7$ years). All censuses were prior to the $2015-16$ very strong El Niño event, as 521 we expected that event to supress carbon gains relative to the long-term mean.

522 Forest inventory plots were sampled using standardised protocols (36), where all live stems with 523 diameter $\geq 100 \mathrm{~mm}$ were measured at $1.3 \mathrm{~m}$ or $50 \mathrm{~cm}$ above buttresses and deformities. Trees were 524 tagged so that the same tree could be identified in subsequent censuses. In some cases the point of 525 diameter measurement (POM) had to be moved due to upward growth of buttresses and deformities.

526 For these trees we use the $\mathrm{D}_{\text {mean }}$ approach from Talbot et al. (37).

527 In a few cases (6 plots) the minimum diameter measured changed over time, or palms and

528 Phenakospermum were excluded in some censuses. For these, we estimated aboveground biomass

529 (AGB, subsequently converted to carbon stocks) and aboveground woody production (AGWP,

530 subsequently converted to carbon gains) using a minimum diameter or taxonomic protocol that could

531 be consistently applied across censuses, and scaled these values by the aboveground biomass ratio

532 between that protocol and all stems $\geq 100 \mathrm{~mm}$ protocol for censuses when all stems were measured.

533 Some plots had nested designs where the plot was split into subplots with different minimum diameter 534 protocols (69 plots). For these, we only analysed the area conforming to our minimum diameter 535 protocol. For analysis, we grouped small $(\leq 0.5 \mathrm{ha})$ plots within $1 \mathrm{~km}$ of each other, and also grouped 
Supporting information for Sullivan et al.

536 contiguous larger plots (18 plots), as these will experience equivalent climate and larger plots are less

537 sensitive to stochastic tree fall events (38).

538 Data were curated in ForestPlots.net $(39,40)$, or were subject to equivalent offline handling, and 539 experienced the same quality control procedures. Details of quality control procedures are described 540 in Brienen et al. (41). Our final dataset consists of 590 sampling units (hereafter plots) covering 637.2

541 ha, with 2.2 million measurements of 670,499 unique stems. For validating models of carbon stocks 542 an additional dataset of 223 single-census plots using the same measurement protocols was assembled 543 from the same networks (see section "Validation with independent single-census plot dataset" below).

$545 \quad$ Estimating above-ground biomass

546 Diameter measurements were converted to estimates of aboveground biomass (AGB). For dicot trees 547 we used the allometric equation

$548 \quad \mathrm{AGB}=0.673 \times\left(\rho D^{2} H\right)^{0.976}$,

549 from Chave et al. (42), where $\rho$ is wood density (from $(43,44)$ ) and $H$ is tree height estimated using 550 allometric equations described below. For monocots and tree ferns, we used a palm-specific 551 allometric equation

$\ln (\mathrm{AGB})=-3.3488+2.7483 \cdot \ln (D)$

from Goodman et al. (45), where $D$ is the measured diameter.

The heights of a subset of trees in our dataset were measured in the field, either with a laser rangefinder, hypsometer, or clinometer, or directly by climbing the tree. We filtered this dataset to stems with measured diameters, height $\leq 90 \mathrm{~m}$, diameters $\geq 90 \mathrm{~mm} \mathrm{DBH}$, as height-diameter

557 allometries of saplings differ from those of more mature trees, and to stems that were not broken, 558 leaning or fallen. This gave a total of 78,899 height measurements. We used this dataset to fit local height-diameter allometric models, as these refine AGB estimates by capturing spatial variation in height-diameter allometries missed by large-scale allometric models (46). Height data were not 
Supporting information for Sullivan et al.

561 available from every plot, so to ensure consistent treatment of plots height-diameter models were

562 constructed for each biogeographic region. We fitted three parameter asymptotic models (47) of the

563 form

$564 \quad H=a\left(1-\exp \left(-b D^{C}\right)\right)$,

565 where $a, b$ and $c$ are estimated parameters ('Weibull' models, 48). We fitted these models either

566 treating each observation equally or with case weights proportional to each trees' basal area. These

567 weights give more importance to large trees during model fitting. We selected the best fitting of these

568 models, determining this as the model that minimised prediction error of stand biomass when

569 calculated with estimated heights or observed heights (46). Weibull models were implemented using

570 the nls function in $\mathrm{R}$ with default settings. Starting values of $a=25, b=0.05$ and $c=0.7$ were chosen

571 following trial and error as they led to regular model convergence. Where models did not converge

572 this was usually because the height-diameter relationship did not reach an asymptote, so in these cases

573 we used the $\log -\log$ model $\ln (H)=a+b(\ln (D))$ to estimate height, where $b$ gives the scaling exponent

574 of a power law relationship between height and diameter. We checked if models gave unrealistic

575 predictions by applying models to predict the height of all trees in the biogeographic region, and

576 excluded models that predicted any tree height $10 \%$ higher than the tallest tree we recorded in that

577 continent.

579 Estimating above-ground woody production

580 We estimated AGWP following Talbot et al. (37). AGWP is comprised of four components, (1) the

581 sum of growth of surviving trees, (2) the sum of AGB of new recruits, (3) the sum of unobserved

582 growth of trees that died during a census interval and (4) the sum of growth of unobserved recruits

583 that entered then died during a census interval. Accounting for the latter two components is necessary

584 to avoid census-interval length effects, as more AGWP in these components will be missed due to the

585 greater mortality of trees that accumulates over longer census intervals. 
Supporting information for Sullivan et al.

586 Components 3 and 4 can be estimated using two quantities that can be calculated from observed stem-

587 dynamics in each plot; per-area annual recruitment $\left(R_{a}\right)$ and per-capita annual mortality $\left(m_{a}\right)$. Per-

588 capita mortality is calculated from the ratio of surviving stems to initial stems, using equation 5 in

589 Kohyama et al. (49). Per-area annual recruitment is calculated using estimated mortality rates and the

590 observed change in the number of stems over a census interval, using equation 11 of Kohyama et al.

591 (49).

592 To estimate the unobserved growth of stems that died during a census interval, we first use plot-level

593 per-capita mortality rates $\left(m_{a}\right)$ to estimate how many trees are expected to have died in each year of

594 the census interval, and from that calculate the mean number of years that trees that died during the

595 census interval would have lived before death. The diameter of tree at death $\left(D_{\text {death }}\right)$ can then be

596 estimated as

$597 \quad D_{\text {death }}=D_{\text {start }} \times G \times Y_{\text {mean }}$

598 where $D_{\text {start }}$ is the diameter at the start of the census interval, $G$ is the plot-level median growth rate of

599 the size class the tree was in at the start of the census interval (size classes are defined as $D<200 \mathrm{~mm}$,

$600400 \mathrm{~mm}>D \geq 200 \mathrm{~mm}$, and $D \geq 400 \mathrm{~mm}$ ) and $Y_{\text {mean }}$ is the mean number of years trees survived in

601 the census interval before dying. The diameter at death is then converted to AGB at death using

602 allometric equations (equation 1, except for ferns and monocots where equation 2 is used), and the

603 unobserved growth is calculated as the difference between AGB at death and AGB at the start of the

604 census.

605 To estimate the growth of recruits that were not observed because they died during the census

606 interval, we first need to estimate the number of unobserved recruits. This can be estimated from per-

607 area annual recruitment $\left(R_{a}\right)$ and per-capita annual mortality $\left(m_{a}\right): R_{a}$ gives the number of stems per ha

608 that recruit in a given year, and the probability of each recruit surviving until the next census $\left(P_{\text {surv }}\right)$ is

$609 P_{\text {surv }}=\left(1-m_{a}\right)^{T}$, where $T$ is the number of years remaining in the census interval. The number of

610 recruits in a given year that survive to the next census is $R_{a}-P_{\text {surv }} R_{a}$. Summing this for each year in a

611 census interval gives the total number of unobserved recruits in that census interval. We then need to 
Supporting information for Sullivan et al.

612

613

614

615

616

617

618

619

620

621

622

623

624

625

626

627

628

629

630

631

632

633

634

635

636

637

estimate how long each recruit was alive for. From $m_{a}$ we can calculate the number of recruits in a given year that died in each subsequent year, and from this calculate the mean life-span of recruits in a given year that died before the next census. The average life-span of unobserved recruits $\left(Y_{\text {mean-rec }}\right)$ is the weighted mean of each cohort's lifespan, weighted by the number of unobserved recruits in each year. Diameter at death is given in $\mathrm{mm}$ by

$D_{\text {death }}=100+\left(G \times Y_{\text {mean-rec }}\right)$

where $G$ is the plot-level median growth rate of the smallest size class (i.e. $D<200 \mathrm{~mm}$ ).

Aboveground biomass of recruits at the time of death is estimated using equation 1 . These corrections for unobserved growth have a marginal impact on AGWP calculations, collectively accounting on average for just $2.3 \%$ of estimated plot-level AGWP.

AGB was calculated for each census, and AGWP was calculated for each census interval, and the time-weighted mean of each was taken to give one value per plot. We used a time-weighted mean to give greater importance to AGB estimates separated by longer census-intervals, as these will be more independent. Estimates of AGB and AGWP were converted to carbon stocks and carbon gains by multiplying by 0.456 (50). Carbon residence time was then estimated as carbon stocks /carbon gains, and represents the length of time carbon resides in living biomass before being passed to the litter and necromass pools (51). Calculations to estimate AGB and AGWP were performed using the R package BiomasaFP (52).

\section{Obtaining environmental data}

Most climate data were obtained from climate data from Worldclim2 (31) as it provides the highest resolution $(\sim 1 \mathrm{~km})$ pantropical climate data, although we note that some regions, such as central Africa, have limited station data. We extracted monthly data for the following variables: mean daily minimum temperature, mean daily maximum temperature, precipitation, solar radiation and wind speed, In addition to calculating the standard series of 19 bioclimatic variables, using the dismo $\mathrm{R}$ package (53), we calculated 1) mean daily maximum temperature, $\mathrm{BIO} 1+\mathrm{BIO} / 2$, 2) mean daily 
Supporting information for Sullivan et al.

638 minimum temperature, $\mathrm{BIO} 1-\mathrm{BIO} 2 / 2,3)$ maximum cumulative water deficit as the minimum across

639 the year of monthly cumulative water deficit $W$,

$640 W_{\mathrm{i}}=W_{\mathrm{i}-1}-\min \left(0, P_{\mathrm{i}}-100\right)$,

641 where $P$ is monthly precipitation in $\mathrm{mm}$, and 100 represents measured evapotranspiration. This

642 calculation was run for a year from the wettest month in the year, starting at a water deficit of zero, 4)

643 the number of months where monthly cumulative water deficit was negative, 5) the number of months

644 where monthly precipitation was below $100 \mathrm{~mm}$ (i.e. less than evapotranspiration), 6) mean annual

645 solar radiation, 7) mean annual wind speed, and 8) vapour pressure deficit (VPD = SVP - vapour

646 pressure, where saturated vapour pressure, $\left.\mathrm{SVP},=0.611 \times \mathrm{e}^{(17.502 \text { temperature }) /(\text { temperature }+240.97)}\right)$. We also

647 obtained data on cloud frequency at $\sim 1 \mathrm{~km}$ resolution from Wilson \& Jetz (54), who processed twice-

648 daily MODIS satellite images. Temperature values were adjusted for differences in altitude between

649 the plot and the $1 \mathrm{~km}$ grid cell used for Worldclim interpolation, as these can differ in topographically

650 diverse regions, using lapse rates, so that $T_{\text {plot }}=T_{\text {worldclim }}+0.005 \times\left(A_{\text {worldclim }}-A_{\text {plot }}\right)$, where $T$ is

651 temperature $\left({ }^{\circ} \mathrm{C}\right)$ and $A$ is altitude (m). Temperature values were also corrected for systematic

652 warming trends. To do this, the mean annual temperature in each grid-cell in each year was extracted

653 from the CRU TS 3.24 dataset (55), and robust linear regression used to estimate grid-cell specific

654 warming rates. These were used to adjust Worldclim 2 temperature values for the difference between

655 the midpoint of plot monitoring and the midpoint of the Worldclim2 climatology.

656 Data on soil texture and chemistry was obtained at $1 \mathrm{~km}$ resolution from the SoilGrids dataset (56),

657 with this resolution selected to match the resolution of the climate data. From this we extracted CEC,

658 representing soil fertility, and percentage clay, representing soil texture. For each soil variable we

659 calculated the depth-weighted average for $0-30 \mathrm{~cm}$.

$660 \quad$ Statistical analysis

661 We used linear models to relate carbon, carbon gains and carbon residence time to environmental

662 explanatory variables. The role of different explanatory variables was assessed using multi-model 663 inference. 
Supporting information for Sullivan et al.

664 Response variables were positively skewed and had positive mean-variance relationships, so were 665 log-transformed to meet the assumption of normality and reduce heterogeneity in variances. The log666 normal nature of forest carbon stocks and dynamics means that there is greater potential for variation 667 when forests are large, which could be due to the non-linear scaling of tree biomass and tree basal 668 area.

669 We selected explanatory variables to represent hypothesised ways in which climate could affect 670 carbon stocks (Table S1). We assessed colinearity within this set of explanatory variables using variance inflation factors (VIF) and pairwise correlations. Because of colinearity, we had to exclude

672 VPD, total precipitation, use only one of MCWD and precipitation in the driest quarter, and could 673 include both minimum and maximum temperature but not mean annual temperature. We used 674 precipitation in the driest quarter rather than MCWD as the latter is zero truncated and so is less amenable to regression analysis. After removing these variables all pairwise correlations (including with soil explanatory variables) were weak enough not to cause problems through collinearity $(\mathrm{r}<0.6$ and $\mathrm{VIF}<3)$.

To account for variation other than in climate we also included soil variables relating to texture (\% clay) and fertility (CEC), and included continent specific intercepts to account for biogeographic variation in carbon. To account for unmeasured environmental gradients (e.g. soil variation not captured by the SoilGrids variables), we used Moran's eigenvector maps as explanatory variables, selecting eigenvectors the corresponded to positive spatial autocorrelation in the distance matrix (57). These variables act as a proxy for unmeasured spatial gradients by capturing positive spatial associations between plots.

Plots differed in their area and the length of time they were monitored for. This is likely to affect the variance of carbon stocks, carbon gains and carbon residence time, as smaller plots or plots only monitored for short periods are more likely to be sensitive to the mortality of a few large trees. To account for this, we used case weights relating to plot area and monitoring period. Following Lewis et al. (58), we selected weights by relating residuals from our linear models to plot area and to plot monitoring period, and subsequently assessing which root transformation of plot area/ monitoring 
Supporting information for Sullivan et al.

691 period removed the pattern in the residuals when used as a weight. Selected weights were: carbon

692 stocks, Area ${ }^{1 / 3}$; carbon gains, Monitoring length ${ }^{1 / 7}$; carbon residence time, Area ${ }^{1 / 9}+$ Monitoring 693 length ${ }^{1 / 12}-1$.

694 We fitted all subsets of the general linear model with explanatory variables described above, forcing spatial eigenvectors into all models. We then averaged the subset of models where $\Delta \mathrm{AIC}<4$, using full averaging so variables that do not appear in the model get the value of zero for their coefficients. This means that model averaged coefficients of terms with limited support exhibit shrinkage towards zero. Multi-model inference was performed using the MuMIn R package (59).

We assessed whether the two climate variables found to have important additive effects on carbon stocks in this analysis (mean daily maximum temperature in the warmest month and precipitation in the driest quarter) interacted with each other by adding an interaction term between these variables to the full generalised linear model of carbon stocks as a function of other climate and soil variables, continent and spatial eigenvectors. We compared these two models using AIC. We repeated this with carbon gains and carbon residence time as response variables.

To assess whether the temperature carbon relationship was non-linear we used breakpoint regression implemented in the segmented $\mathrm{R}$ package (60). This estimates a breakpoint in the explanatory variable at which the slope of the relationship with the response variable changes. We estimated the breakpoint for the mean daily maximum temperature in the warmest month variable in the full model with a temperature-precipitation interaction described above. We assessed the support for the breakpoint by comparing the AIC of the model with a breakpoint with the AIC of a model with a linear relationship. We repeated this with carbon gains and carbon residence time as response variables. variables and spatial eigenvectors using Random Forest decision tree algorithms (22) implemented using the randomForest $\mathrm{R}$ package (61). We assessed variable importance by calculating the average increase in node purity across all decision trees (measured by residual sum of squares) when using the variable to split the data. We assessed modelled relationships between response and explanatory 
Supporting information for Sullivan et al.

717

718

719

720

721

722

723

724

725

726

727

728

729

730

731

732

733

734

735

736

737

738

739

740

variables using partial plots, which show predicted change in the response variable, averaged across trees, when changing the explanatory variable and holding all other variables constant.

To compliment this analysis based on relationships expected a priori, we also performed an exploratory analysis to assess whether other climate variables excluded from the full general linear models had an effect on carbon. To do this, we fitted linear models to assess the bivariate relationship of carbon with each climate variable, with continent also included as an explanatory variable to account for biogeographic variation in forest characteristics.

\section{Validation with independent single-census plot dataset}

We assessed whether the relationships with environmental variables identified in the analyses of multi-census plot data described above held when applied to an additional dataset of 223 singlecensus plots. As the single-census data were not used in any of the analyses above they did not influence modelling decisions, so provide an independent test of the relationships identified with the multi-census plot analysis.

Single-census plots were extracted from the ForestPlots.net database $(39,40)$ using the same plotselection criteria as for the multi-census plots, except that censuses during or following the 2015-16 strong El Niño were included in the single-census plot dataset as we expected that carbon stocks, unlike gains, would still remain close to their long-term mean.

We fitted a general linear model with the five climate explanatory variables, soil fertility and texture, continent and spatial eigenvector, and model averaging of all subsets of this model as described for the multi-census plots. We performed this analysis using just the single-census plots and a combined dataset of single and multi-census plots.

Scaling results to the biome 
Supporting information for Sullivan et al.

741 We applied the relationship between carbon stocks and mean daily maximum temperature in the

742 warmest month identified by the breakpoint regression to estimate the total change in carbon stock

743 due to temperature effects alone for different scenarios of temperature increase. We delimited the

744 biome extent using the WWF tropical and subtropical moist broadleaved forest biome (62), restricted

745 to tropical latitudes, and further refined it by excluding grid-cells with $<50 \mathrm{Mg} \mathrm{C} \mathrm{ha}^{-1}$ using data from

746 (30), as these are unlikely to be forest. Calculations were conducted at 10-minute resolution. For each

747

748

749

750

751

752

753

754

755

756

757

grid-cell we predicted the percentage change in carbon for a given temperature increase from our statistical model, holding all other variables constant. We then used a reference carbon stock map (30) to convert percentage change to change in carbon stocks per hectare (in $\mathrm{Mg} \mathrm{ha}^{-1}$ ). To calculate change in carbon stocks for the whole grid-cell, we multiplied change per hectare by the area of the grid-cell in hectares, and then adjusted this by the proportion of the grid-cell that was forested by multiplying by 2014 forest cover (63). Total change for the biome (in Pg) was calculated by summing these gridcell level values. Uncertainty due to our statistical model was assessed by generating multiple predictions by resampling model parameters (breakpoint threshold, slope below breakpoint, slope above breakpoint), and extracting quantiles from the resultant distribution of predicted change values. Aboveground biomass carbon values were scaled to include root biomass based on a root to shoot ratio of 0.19 in tropical evergreen forests (64).

The Avitabile et al (30) aboveground biomass map was chosen to provide reference carbon stocks. While other maps have previously been produced by Saatchi et al. (65) and Baccini et al. (66) we selected the Avitabile map because it synthesises the earlier maps (see Mitchard et al. (67) for discussion of substantial differences between these maps) and is anchored by more field data. Importantly, the Avitabile map reproduces spatial patterns in aboveground biomass that have been described from field data but are absent in the Saatchi or Baccini maps, including the much higher biomass density of north-east Amazonian forests due to tall trees and very high wood density (68). Nevertheless, we also investigated the consequences of using the Saatchi or Baccini maps for our estimates of biomewide thermal sensitivity and spatial patterns of change in carbon stocks (Fig S15). 
Supporting information for Sullivan et al.

767 We investigated three temperature change scenarios. Firstly, we applied a $1^{\circ} \mathrm{C}$ increase to all

768 locations. Secondly, we assessed the consequence of a $1.5^{\circ} \mathrm{C}$ increase in global temperature from pre-

769 industrial levels for the equilibrium temperature response of tropical forest carbon. Finally, we

770 assessed the consequence of a $2^{\circ} \mathrm{C}$ increase in global temperature from pre-industrial levels. For the

771 latter two we obtained data from CMIP5 climate models, using downscaled future climate projections

772 based on the Worldclim climatology (69). As downscaling was performed using Worldclim version

$7731.4(70)$ and our statistical models use Worldclim version 2, we calculated the warming anomaly in

774 each grid-cell from the current Worldclim version 1.4 conditions, and applied this to the Worldclim 2

775 data to obtain future temperature. RCP scenarios and time-points were chosen to give global

temperature increases that best match $1.5^{\circ} \mathrm{C}$ and $2^{\circ} \mathrm{C}$ above pre-industrial. For $1.5^{\circ} \mathrm{C}$ we used RCP 2.6

averaged for 2040-2060 (median temperature increase across models $=1.5^{\circ} \mathrm{C},(71)$ ). For $2^{\circ} \mathrm{C}$, we used

RCP 2.6 averaged for $2040-2060$ (median temperature increase models $=1.9^{\circ} \mathrm{C}(71)$ ). Note that

predicted increases in maximum temperatures were often considerably greater than the global increase, especially in South America. For both scenarios we used the median predicted temperature change for each grid-cell from an ensemble of 15 models (BCC-CSM1-1, CCSM4, CNRM-CM5,

We assessed the potential for long-term carbon dioxide growth stimulation to offset these long-term ppm and 487 ppm respectively (73). We cannot assess the effect of $\mathrm{CO}_{2}$ on biomass from our spatial dataset, so instead used independent estimates of $\mathrm{CO}_{2}$ effects from other sources. Firstly, we obtained $\mathrm{CO}_{2}$ only effects on net primary production (NPP) extracted from an ensemble of CMIP5 earth system models by (74). This gives the proportional change in NPP for evergreen forests (note that this also includes boreal forests) over 1980-2010, standardised to a 100 ppm increase in $\mathrm{CO}_{2}$ concentration. To propagate this through to changes in AGB under future $\mathrm{CO}_{2}$ conditions we first estimated the 
Supporting information for Sullivan et al.

794

795

796

797

798

799

800

801

802

803

804

805

806

807

808

809

810

811

812

813

814

815

816

817

818

logarithmic dependency of NPP on $\mathrm{CO}_{2}$ (75) by substituting values of NPP and $\mathrm{CO}_{2}$ at time zero and $t$ (from (74)) into the equation,

$$
N P P_{t}=N P P_{0}\left\lceil 1+\beta \ln \left(\frac{\left\lfloor\mathrm{CO}_{2}\right\rfloor_{t}}{\left[\mathrm{CO}_{2}\right\rfloor_{0}}\right)\right\rceil
$$

This equation can be used to compute NPP annually given an initial NPP estimate and a time series of atmospheric $\mathrm{CO}_{2}$ concentrations (from a combination of the observed record from pre-industrial and the RCP 4.5 scenario, modified so that it stabilises at 487 or 443 ppm depending on warming scenario). Initial pre-industrial NPP was back-calculated from present-day values using Equation 7 , with 13.3 $\mathrm{Mg} \mathrm{C} \mathrm{ha}^{-1} \mathrm{yr}^{-1}$ (mean of nine Amazon plots where NPP has been measured, from (76)) used for present-day NPP. To propagate NPP into change in woody biomass (following (51)) we used the equation

$\frac{d M_{\mathrm{wood}}}{d t}=\alpha_{\mathrm{wood}} N_{\mathrm{P}}-\frac{M_{\mathrm{wood}}}{\tau_{\mathrm{wood}}}$

where $M_{\text {wood }}$ is woody biomass, $N_{p}$ is NPP, $\alpha_{\text {wood }}$ is the allocation of NPP to wood (taken as 0.33 , the mean value across nine plots from (76)) and $\tau_{\text {wood }}$ is the residence time of woody biomass, taken as 59.1 years (the median value across plots used in this study). This model (equations 7 and 8) was run from pre-industrial to 2500, enabling us to see the equilibrium effect of increased $\mathrm{CO}_{2}$ concentrations on biomass, assuming temporally invariant allocation and residence time. We calculated the proportional change in biomass from 2000 to 2500 , and applied this to the reference carbon stock map to obtain predicted equilibrium change in aboveground biomass due to $\mathrm{CO}_{2}$ effects.

The effects of $\mathrm{CO}_{2}$ in earth system models have been reported to be larger than those deduced from satellite data or $\mathrm{CO}_{2}$ enrichment experiments (74), so we also ran the above model using changes in NPP reported from a synthesis of free-air $\mathrm{CO}_{2}$ enrichment experiments conducted in forests (74). Finally, we looked at the impact of using $\mathrm{CO}_{2}$ effects derived from a recent large meta-analysis of $\mathrm{CO}_{2}$ enrichment experiments (77), which reported a $12.5 \%$ increase in biomass of tropical trees for a $250 \mathrm{ppm}$ increase in $\mathrm{CO}_{2}$ concentration. As this relationship was reported to be linear (77) we used linear interpolation to estimate the change in biomass under $\mathrm{CO}_{2}$ concentrations associated with each 
Supporting information for Sullivan et al.

819 warming scenario (i.e. 443 and 487 ppm). To estimate long-term changes in biomass accounting for 820 both temperature and carbon dioxide, we first applied the $\mathrm{CO}_{2}$ relationship to estimate the change in 821 biomass due to carbon dioxide growth stimulation, and then assessed the effects of warmer

822 temperatures from this revised baseline. Our approach allows a simple assessment of $\mathrm{CO}_{2}$ effects

823 exploring a range of different effect strengths. Real-world responses will likely be more complex,

824 with, for example, nutrient limitation potentially affecting the extent to which growth is stimulated by $825 \mathrm{CO}_{2}(77)$.

826

827

828 


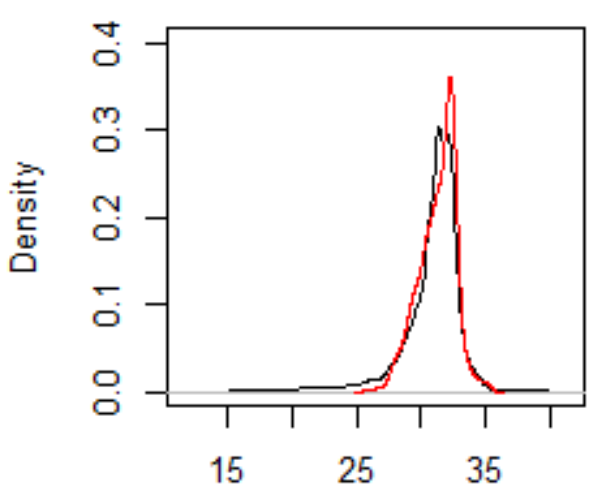

Maximum temperature $\left({ }^{\circ} \mathrm{C}\right)$

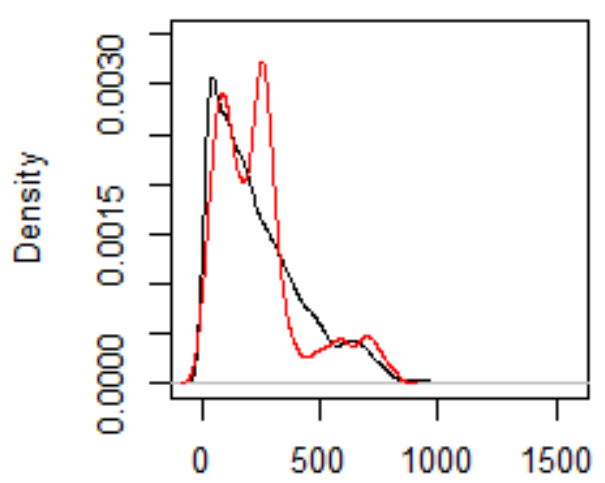

Precipitation, driest quarter $(\mathrm{mm})$

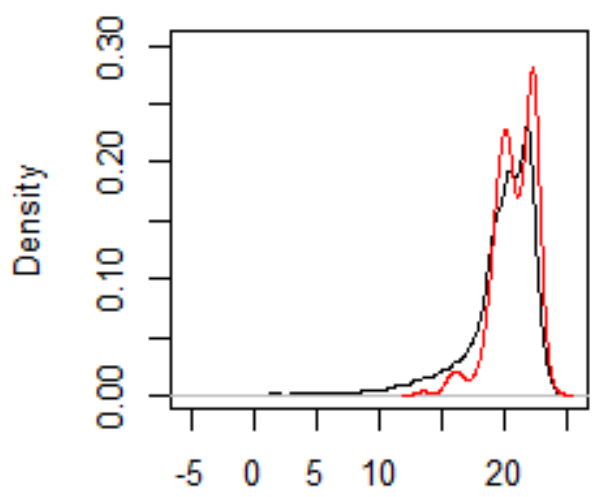

Minimum temperature $\left({ }^{\circ} \mathrm{C}\right)$

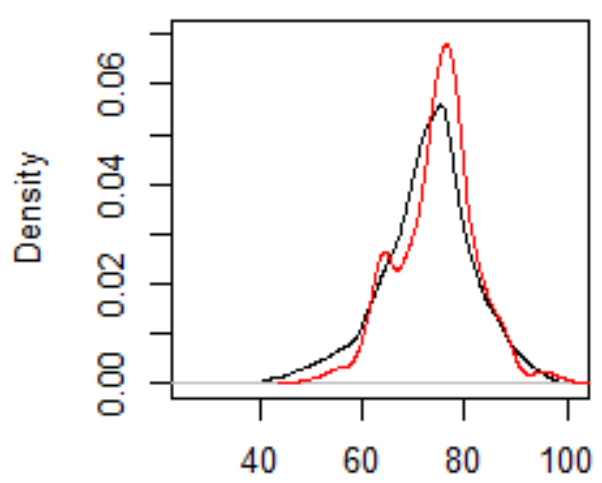

Cloud cover (\%)

Figure S1. Climate space represented by our plot network. Red lines show the probability density

831 function of each variable in our multi-census plot network. Black lines show the probability density

832 across 10 minute grid-cells in the biome, restricted to areas with forest cover in GLC 2000 (78). 
(a)

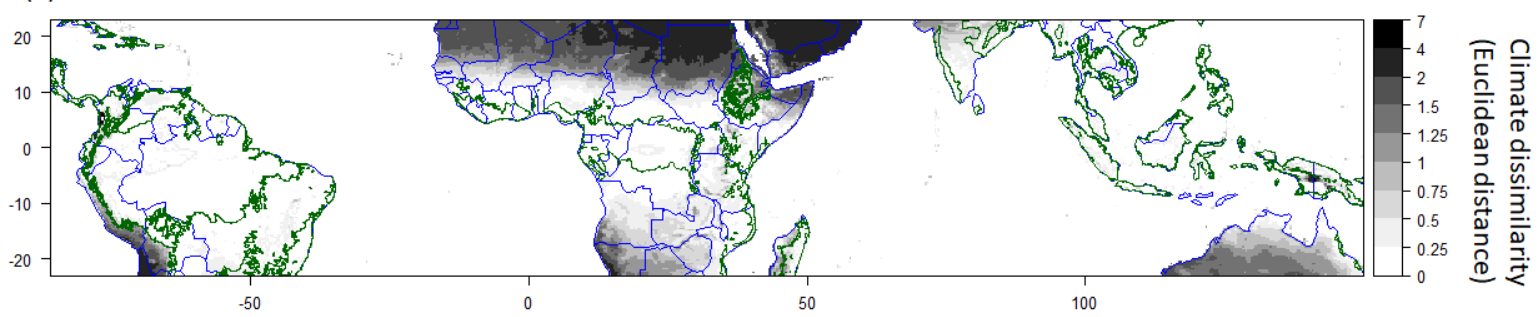

(b)
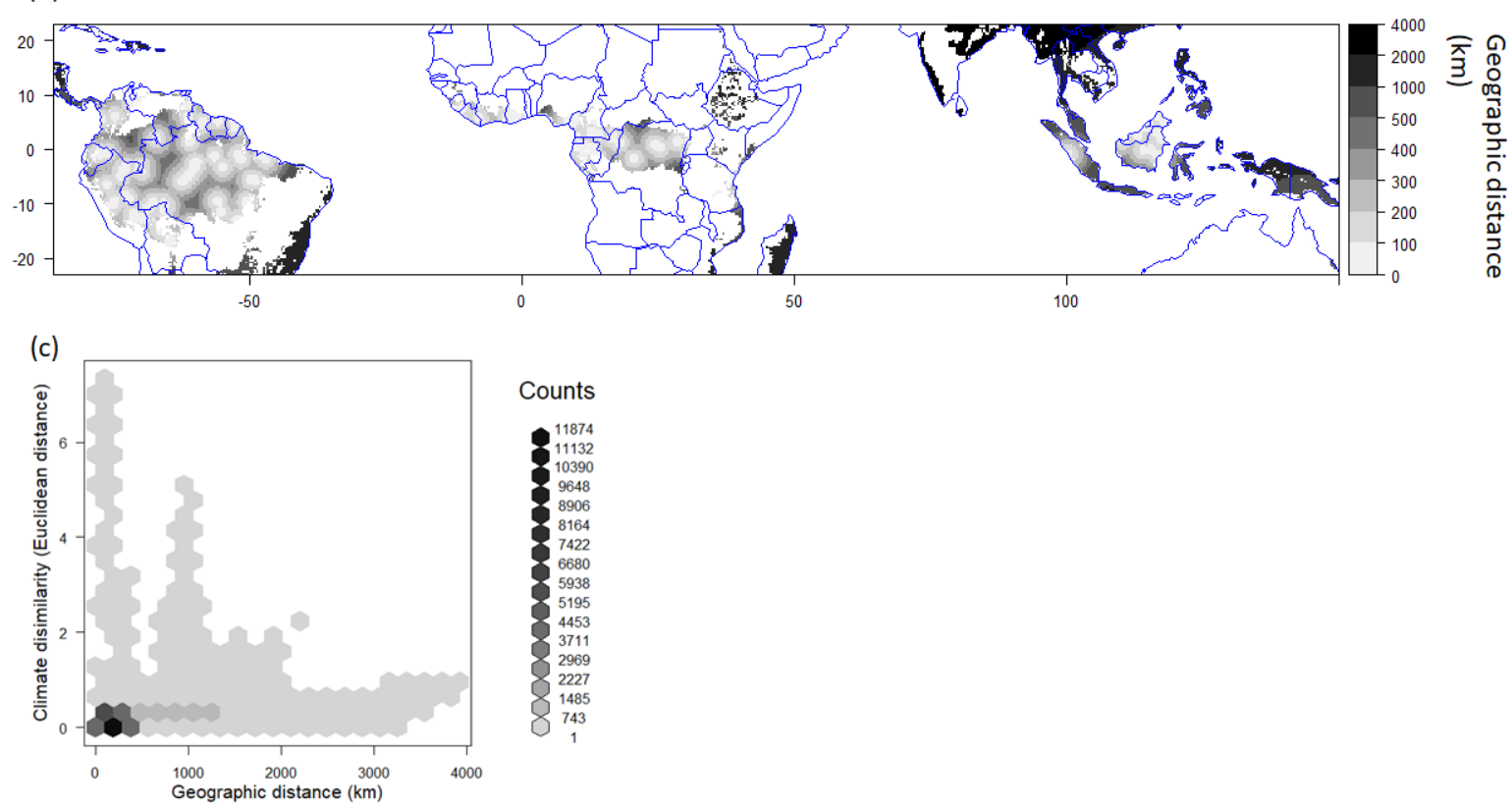

Figure S2. Ability of our plot network to represent the climate conditions found in the moist tropical forest biome. (a) Minimum climate dissimilarity (measured as Euclidean distance on climate variables scaled by their standard deviation) between 10 minute grid cells and the multi-census plot network.

839 Climate variables used are the same as in Fig. 2. Green lines indicate the extent of the biome. (b)

840 Geographic distance $(\mathrm{km})$ between grid cells and the multi-census plot network. (c) Relationship

841 between climatic and geographic distance of 10 minute grid cells across the tropical forest biome to

842 our plot network. The lack of relationship between climate dissimilarity and geographical distance,

843 alongside the mostly low climatic dissimilarities, shows that our sampling is sufficient to capture the

844 environmental space of the biome and that we can reasonably extrapolate to geographically distant

845 areas from our plots, which are in any case largely deforested already and hence contribute very little

846 to our projected biome-wide carbon response to climate change. (These tropical moist forest areas that

847 are poorly sampled and largely lost include the Atlantic Forests in Brazil, Andean Forests in western 
Supporting information for Sullivan et al.

848 South America, eastern Caribbean, Madagascar, and much of tropical South Asia, south China,

849 continental Southeast Asia, Philippines, Sumatra and Java). 


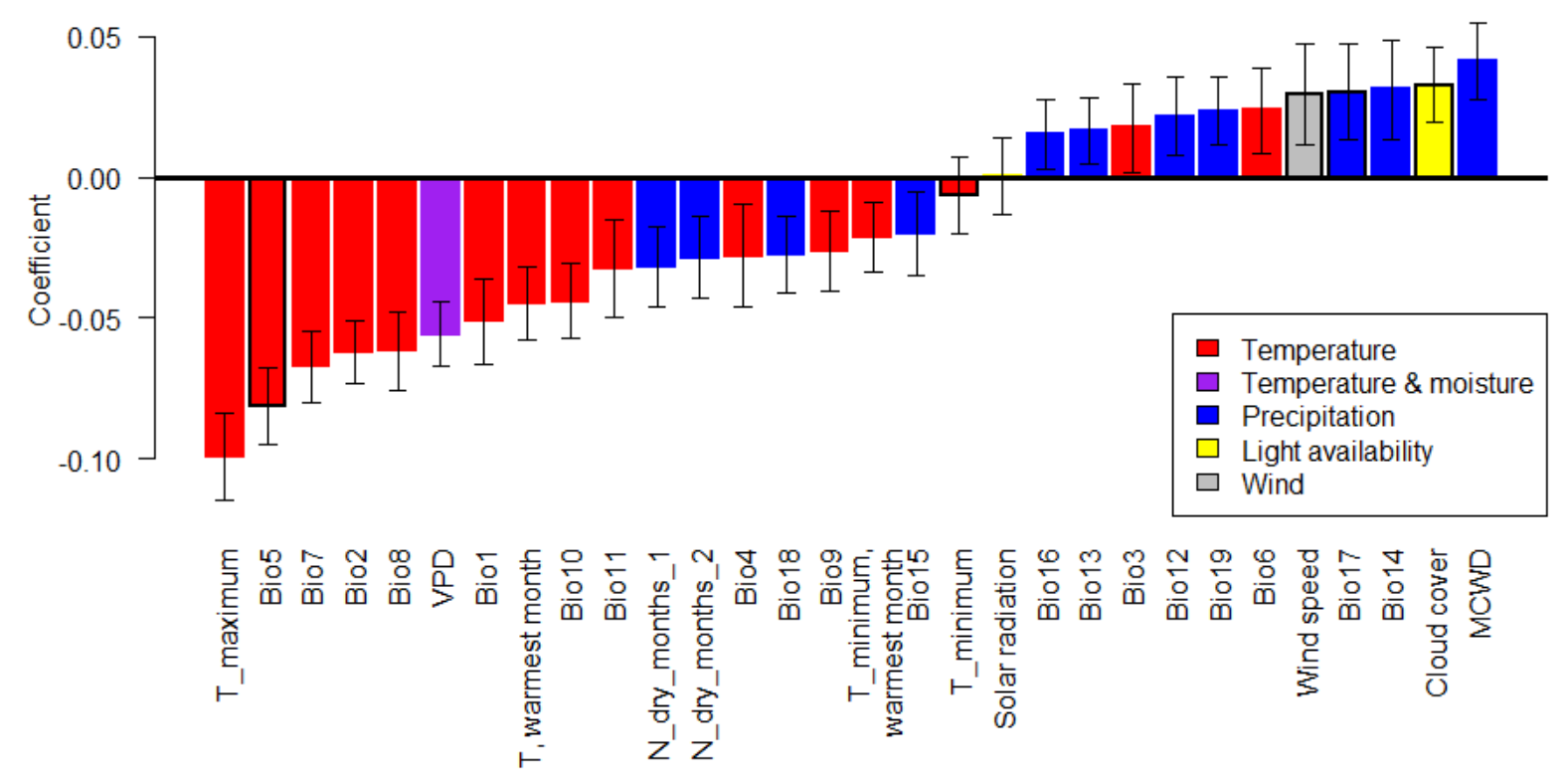

851

Figure S3. Relationships between individual climate variables and tropical forest aboveground carbon stocks. Standardised coefficients are from models with the climate variable and continent as explanatory variables and show change in $\ln$ (carbon) for a standard deviation change in the explanatory variable. Error bars show standard errors. Variables used in the main analysis have black outlines. Full variable names are: T_maximum - mean daily maximum temperature, Bio5 - mean daily maximum temperature in the warmest month, Bio7 - annual temperature range, Bio2 - mean diurnal temperature range, Bio8 - mean temperature in the wettest quarter, VPD - vapour pressure deficit, Bio1 - mean annual temperature, Bio10 - mean temperature in the warmest quarter, Bio11 mean temperature in the coldest quarter, N_dry_months_1 - number of months with negative cumulative water deficit, N_dry_months_2 - number of months where precipitation is less than evapotranspiration, Bio4 - temperature seasonality, Bio18 - precipitation in the warmest quarter, Bio9 - mean temperature in the driest quarter, T_minimum warmest month - mean daily minimum temperature in the warmest month, Bio15 - precipitation seasonality, T_minimum - mean daily minimum temperature, Bio16 - precipitation in the wettest quarter, Bio13 - precipitation in the wettest month, Bio3 - isothermality, Bio12 - annual precipitation, Bio19 - precipitation in the coldest quarter, Bio6 - mean daily minimum temperature in the coldest month, Wind speed - mean daily 
Supporting information for Sullivan et al.

868 wind speed, Bio17 - precipitation in the driest quarter, Bio14 - precipitation in the driest month,

869 Cloud cover - proportion of MODIS passes with cloud present, MCWD - maximum cumulative

870 water deficit (note this is negative when water deficit is high, so a positive relationship with MCWD

871 indicates higher carbon when water deficits are less).

872

873 

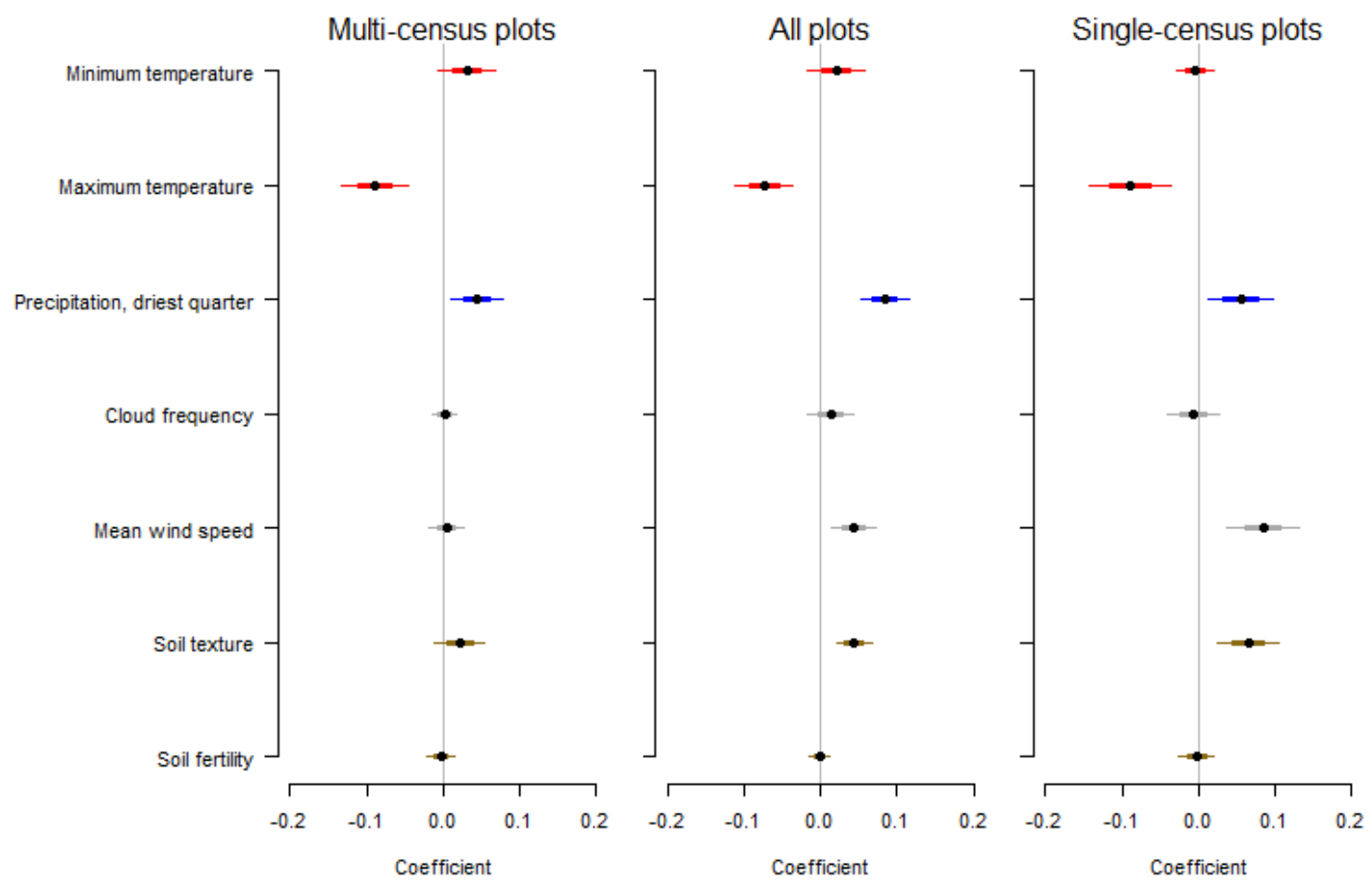

Figure S4. Validation of tropical forest carbon stock sensitivity model against an independent dataset

878 of 223 single-census plots from our networks measured with the same protocols. Model-averaged

879 shrinkage adjusted coefficients from multiple regression models of biomass carbon stocks as a

880 function of climate, soil, biogeography and spatial eigenvectors. Models were either fitted to the

881 multi-census plot dataset (as in Fig. 2), to the single-census plot dataset, or to the combined dataset.

882 This analysis shows that the relationships identified to be most important in the main multi-census plot analysis (i.e. the negative relationship between carbon stocks and maximum temperature and

884 positive relationship with precipitation in the driest quarter) are also found in an independent dataset,

885 which was not used for preliminary analysis so did not influence the choice of explanatory variables. 
Supporting information for Sullivan et al.

887
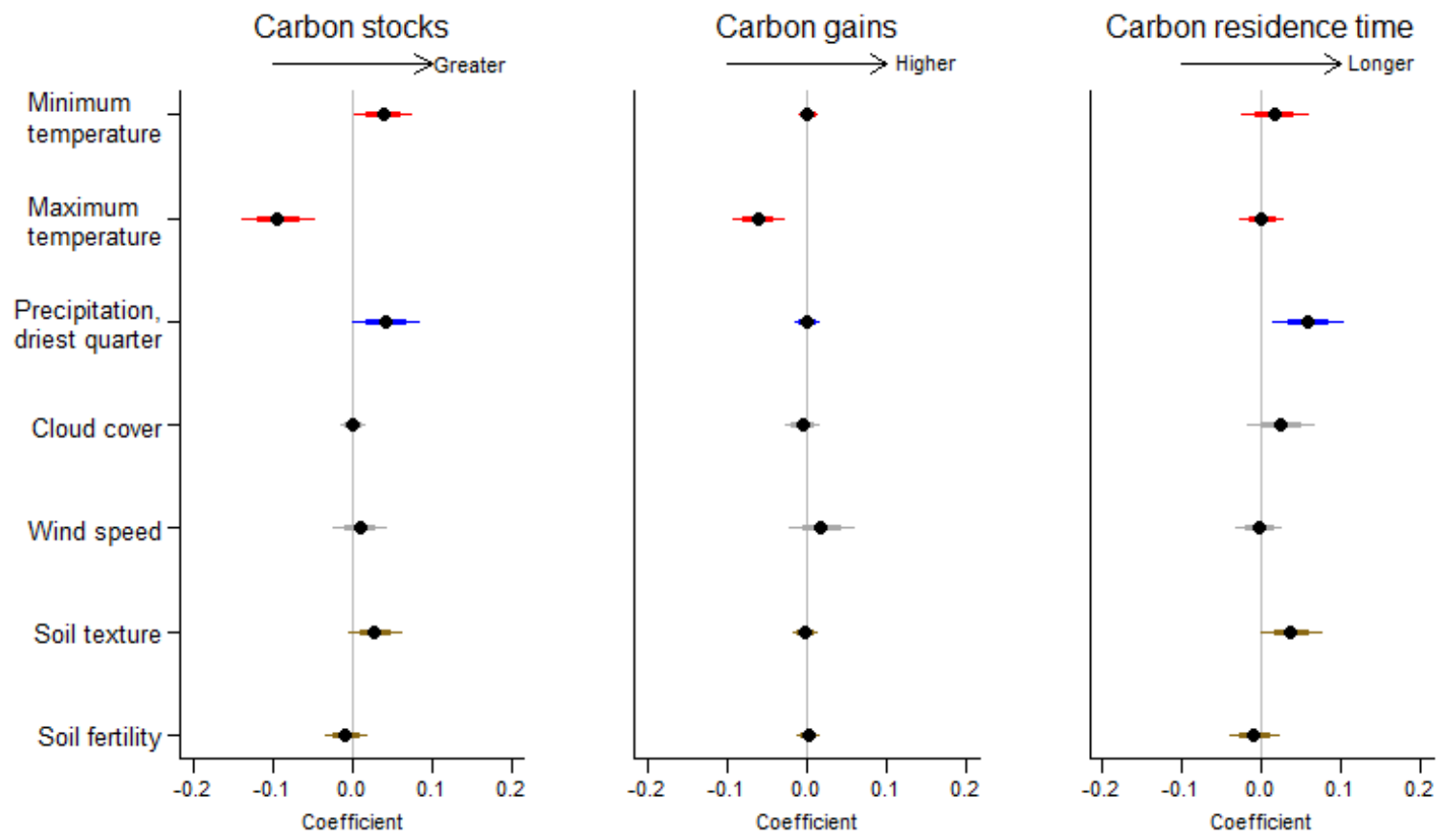

888 Figure S5. As Figure 2, but with aboveground biomass estimated using the Chave et al. 2005 (79)

889 moist forest allometric equation, which does not include a height term and is instead based on a third-

890 order polynomial relationship between diameter and aboveground biomass. This indicates that our

891 results are robust to using an alternative allometry to estimate aboveground biomass.

892 


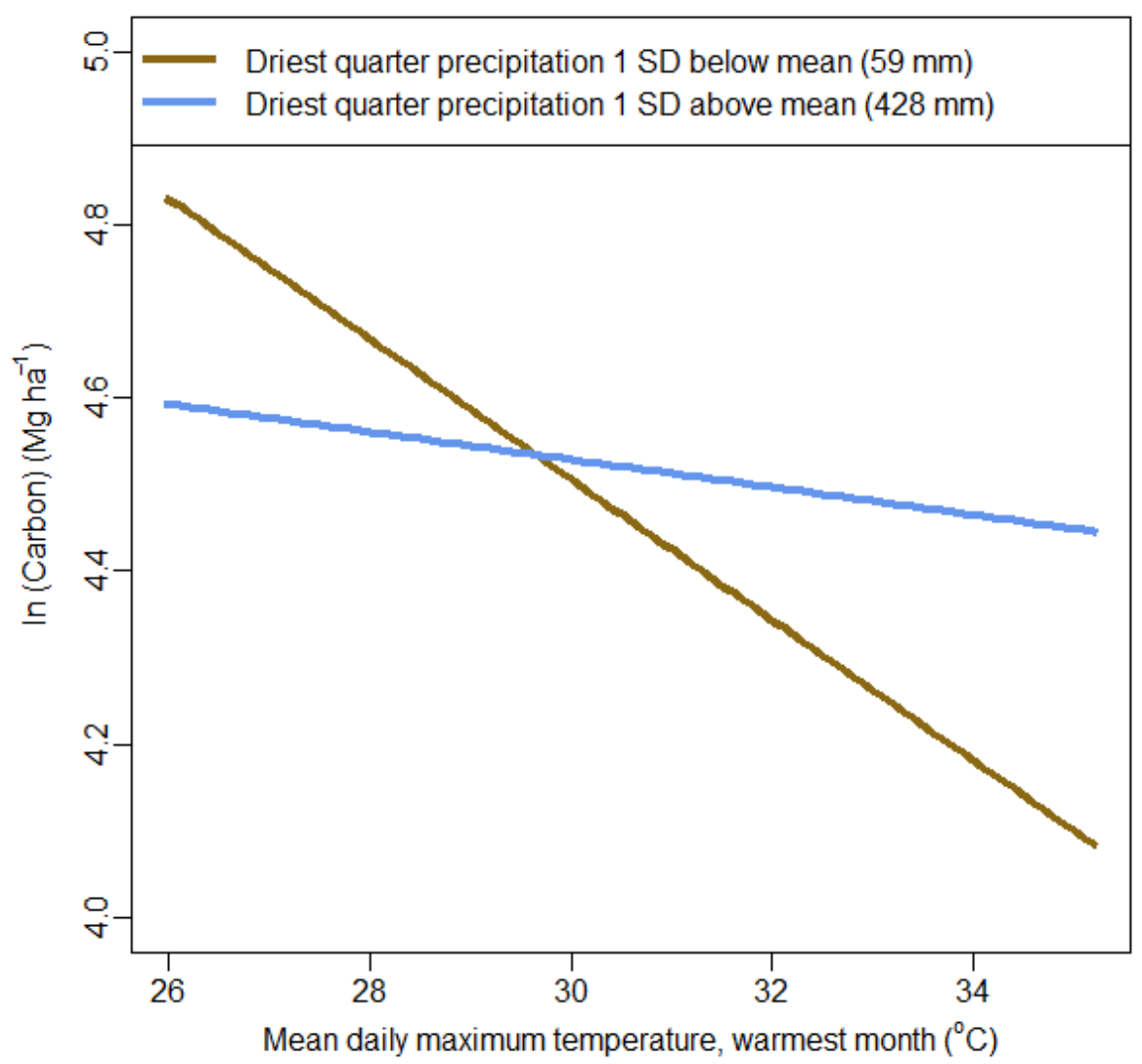

895

896 Figure S6. Interaction between mean daily maximum temperature in the warmest month and

897 precipitation in the driest quarter in determining aboveground tropical forest carbon stocks. Modelled 898 relationships with temperature are shown holding precipitation either one standard deviation above or below the mean. Note that the temperature-carbon relationship is steeper when precipitation is low.

900 

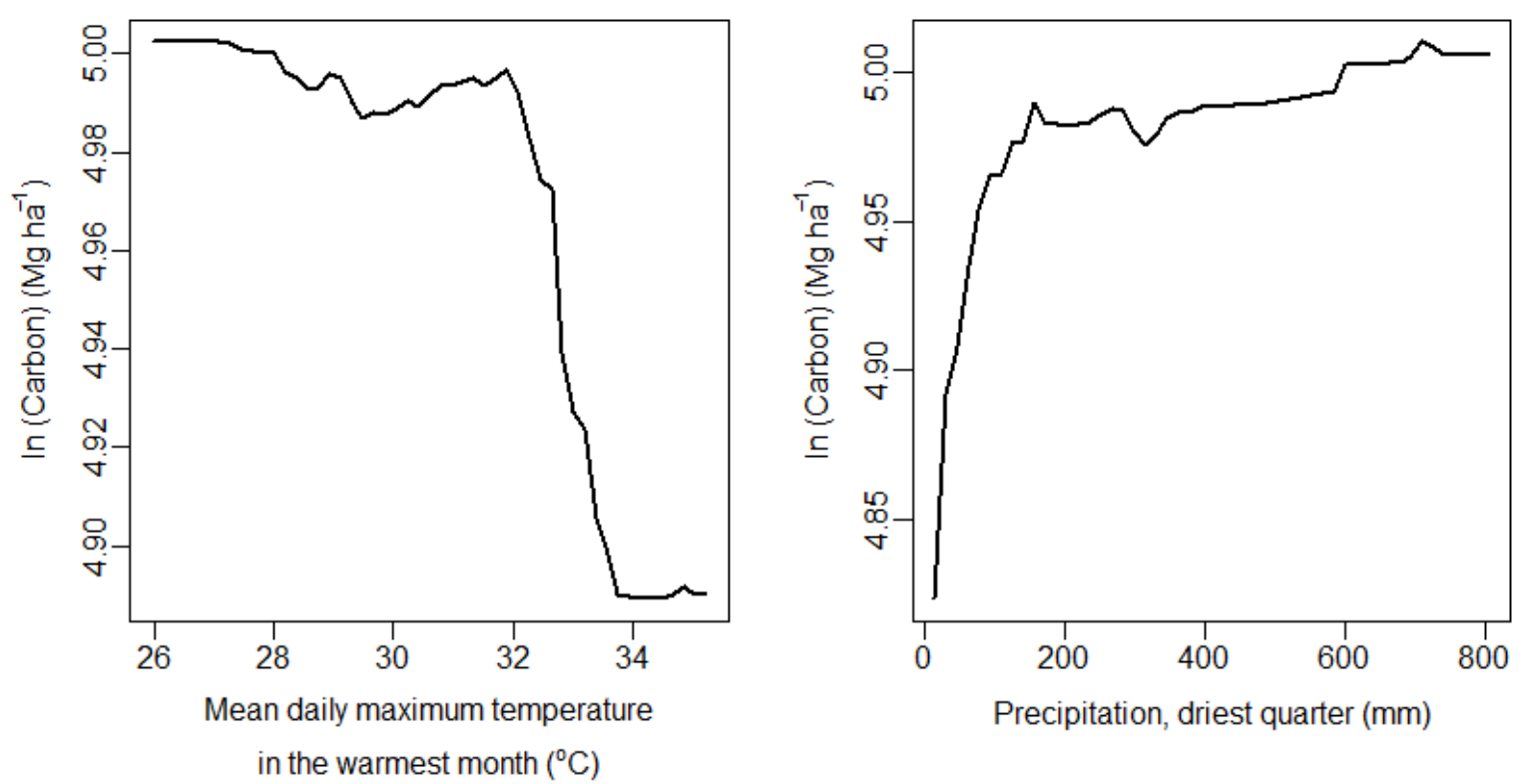

902

903 Figure S7. Partial relationships between tropical forest carbon stocks and the two climate variables identified to be most important by the random forest decision tree algorithm. Partial plots show predicted values of carbon stocks averaged across an ensemble of decision tree models when changing the explanatory variable of interest and holding other variables constant. The importance of variables in random forest analysis is assessed by calculating the average increase in node purity across all decision trees (measured by residual sum of squares) when using the variable to split the data. Higher values indicate greater importance. Maximum temperature increased node purity by 4.8 and precipitation by 4.7. For all other climate variables increases in node purity were $<3.5$. 

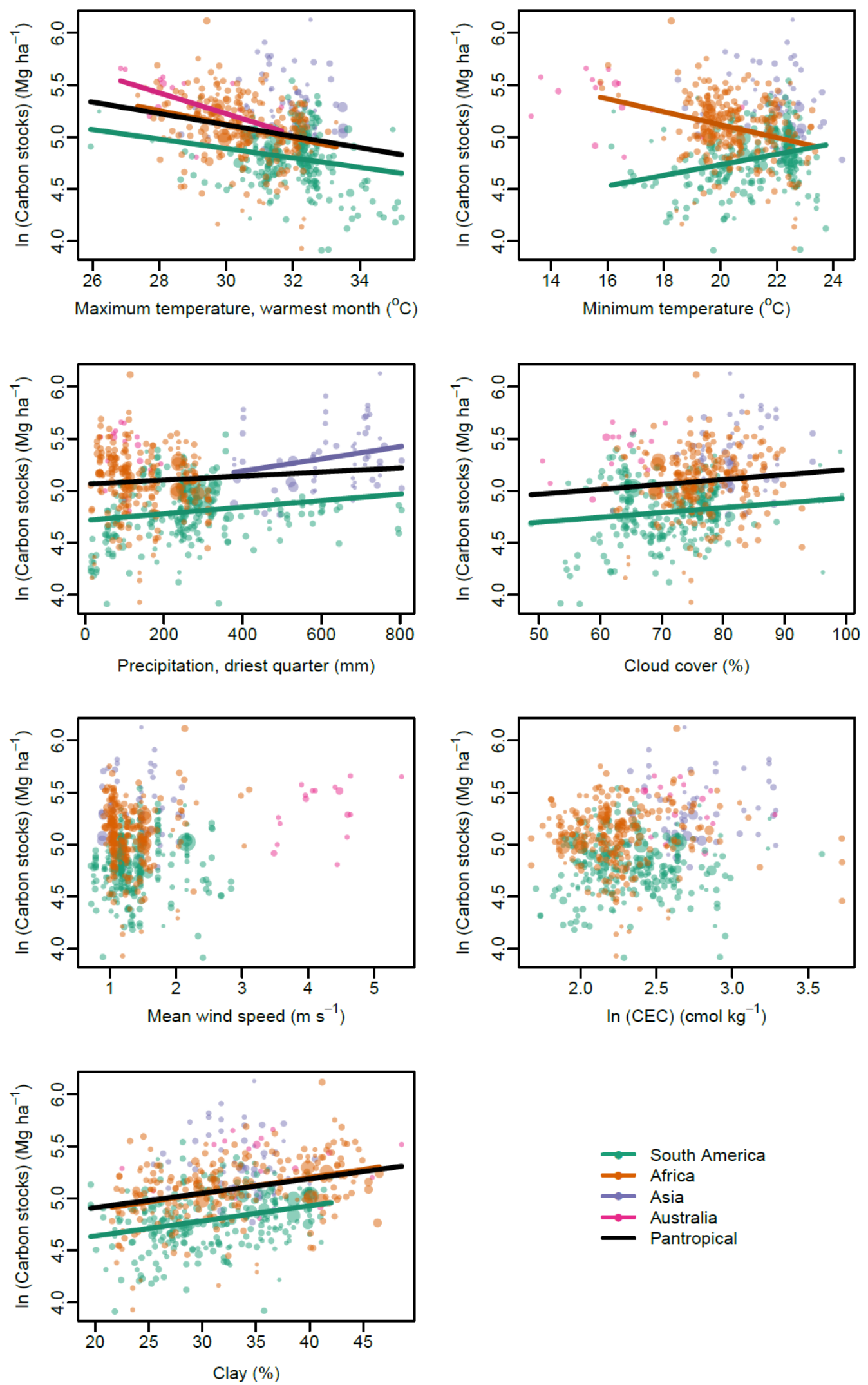

913 Figure S8. Relationships between aboveground tropical forest carbon stocks and environmental predictors. Symbols and colours as in Fig. 3. Coloured lines show bivariate relationships in each 
Supporting information for Sullivan et al.

915 continent, and black lines show pan-tropical relationships also accounting for the effect of continent.

916 Lines are only plotted where statistically significant.

917 

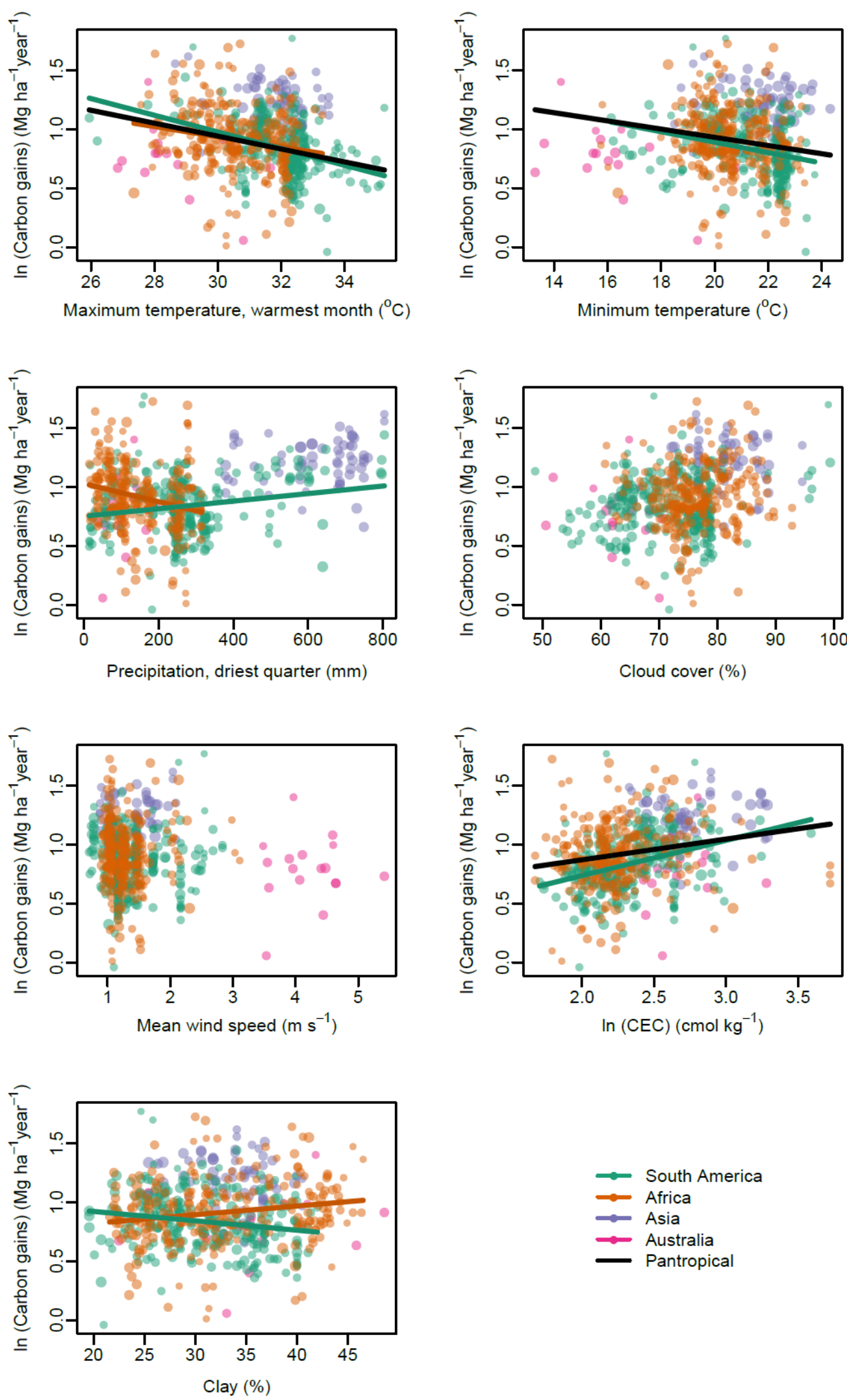

920 Figure S9. As Fig. S8, but showing relationships with carbon gains. 

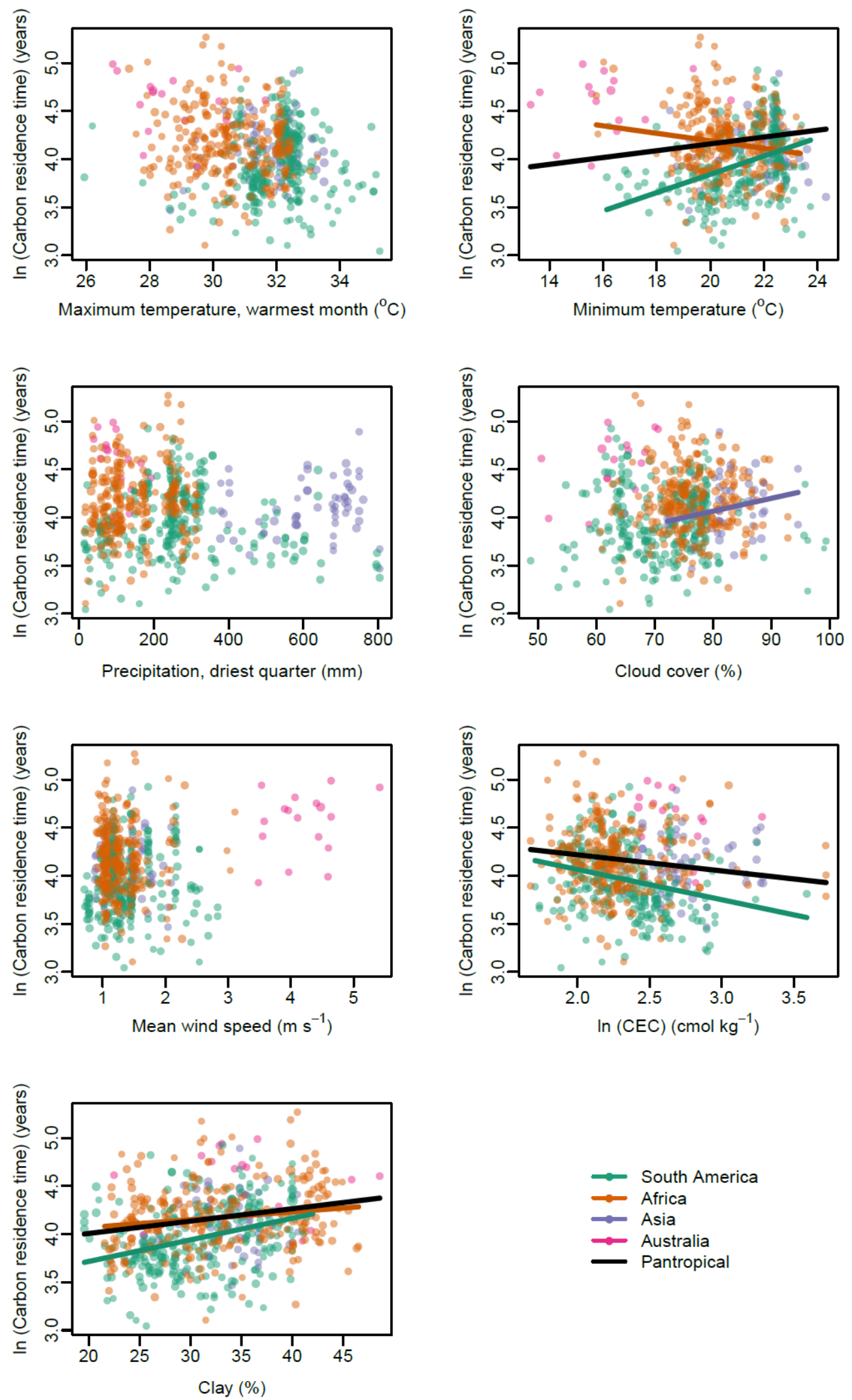

922 Figure S10. As Fig. S8, but showing relationships with carbon residence time. 

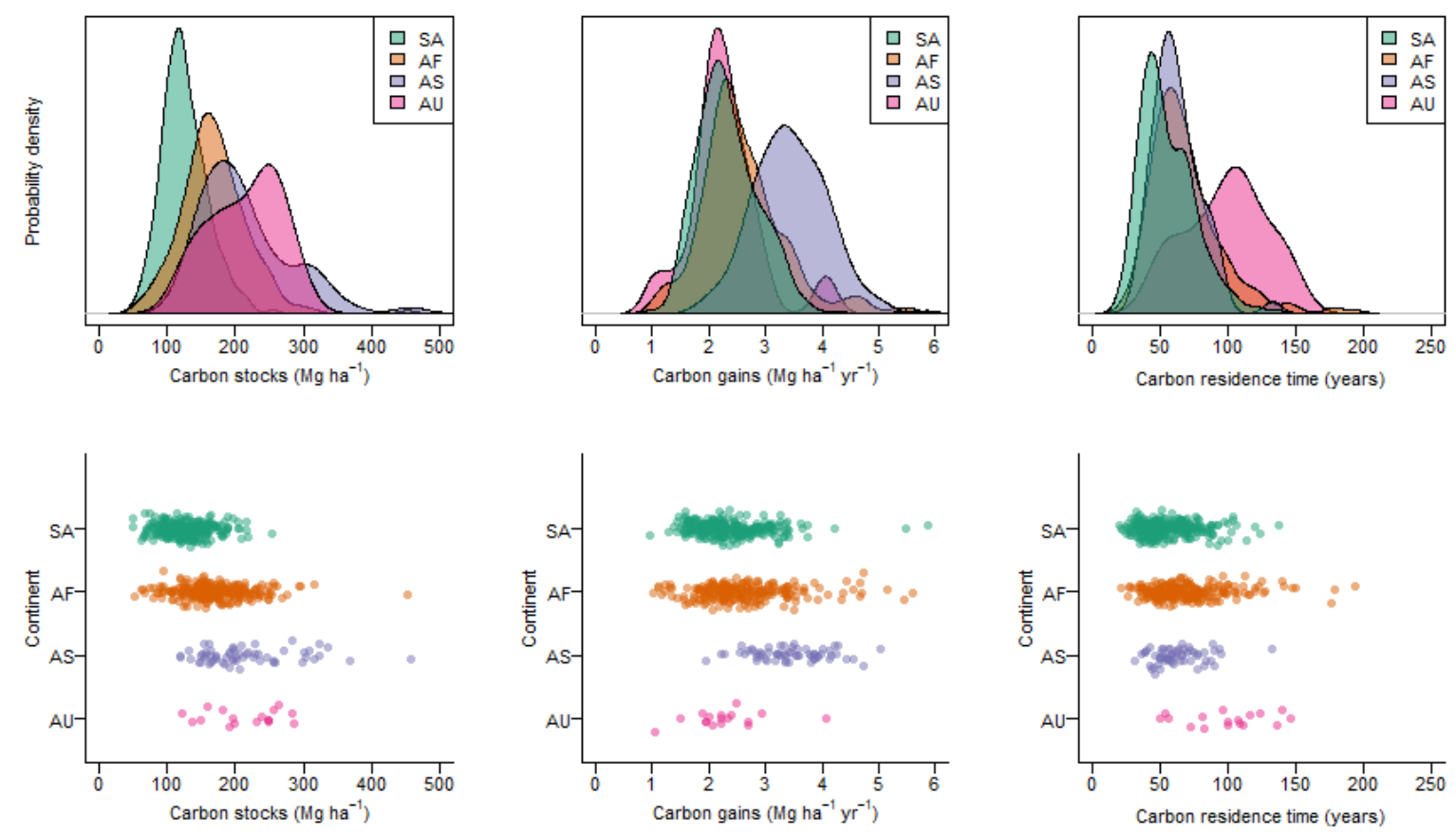

925 Figure S11. Variation in tropical forest aboveground carbon stocks, gains and residence time within 926 and amongst continents. Data are presented as empirical probability density functions (top row) and 927 dot-plots showing raw data points for all our multi-census plots (bottom row). SA = South America, $\mathrm{AF}=$ Africa $, \mathrm{AS}=\mathrm{Asia}, \mathrm{AU}=$ Australia. 


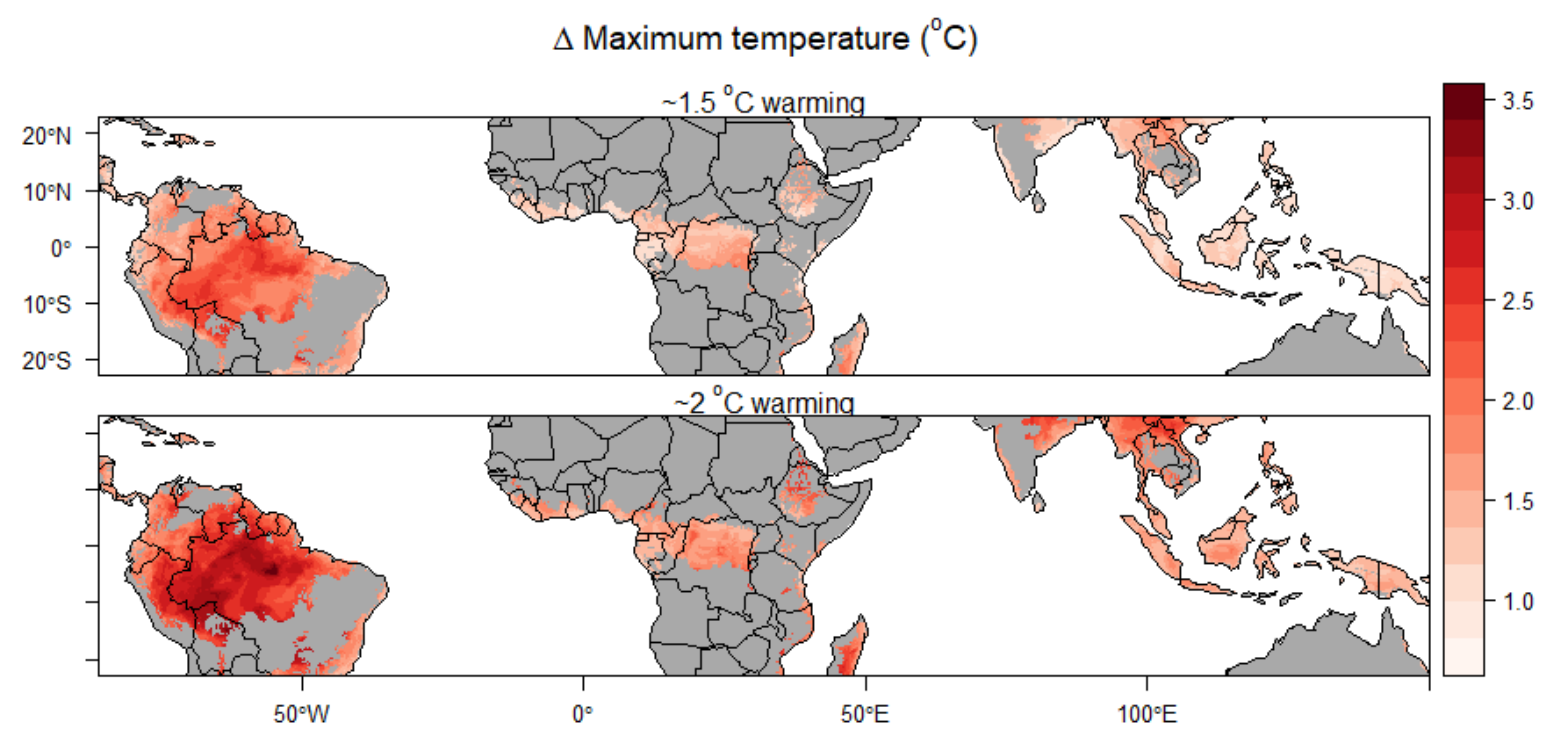

931 Figure S12. Biome-wide change in mean daily maximum temperature in the warmest month from

932 present conditions (based on the Worldclim climatology, 1970-2000), given global increases in

933 temperature of approximately $1.5^{\circ} \mathrm{C}$ and $2^{\circ} \mathrm{C}$ above pre-industrial levels. These levels of global

934 temperature increase are obtained from, respectively, RCP 2.6, 2040-2060 and RCP 4.5, 2040-2060.

935 Global temperature increases of 1.5 and $2^{\circ} \mathrm{C}$ above pre-industrial levels (so $\sim 0.8{ }^{\circ} \mathrm{C}$ and $\sim 1.3{ }^{\circ} \mathrm{C}$

936 above our current baseline climate) would lead to mean increases in maximum temperature in the

937 warmest month across the tropical forest biome of $1.9^{\circ} \mathrm{C}$ and $2.4^{\circ} \mathrm{C}$ the current baseline climate

938 respectively. 

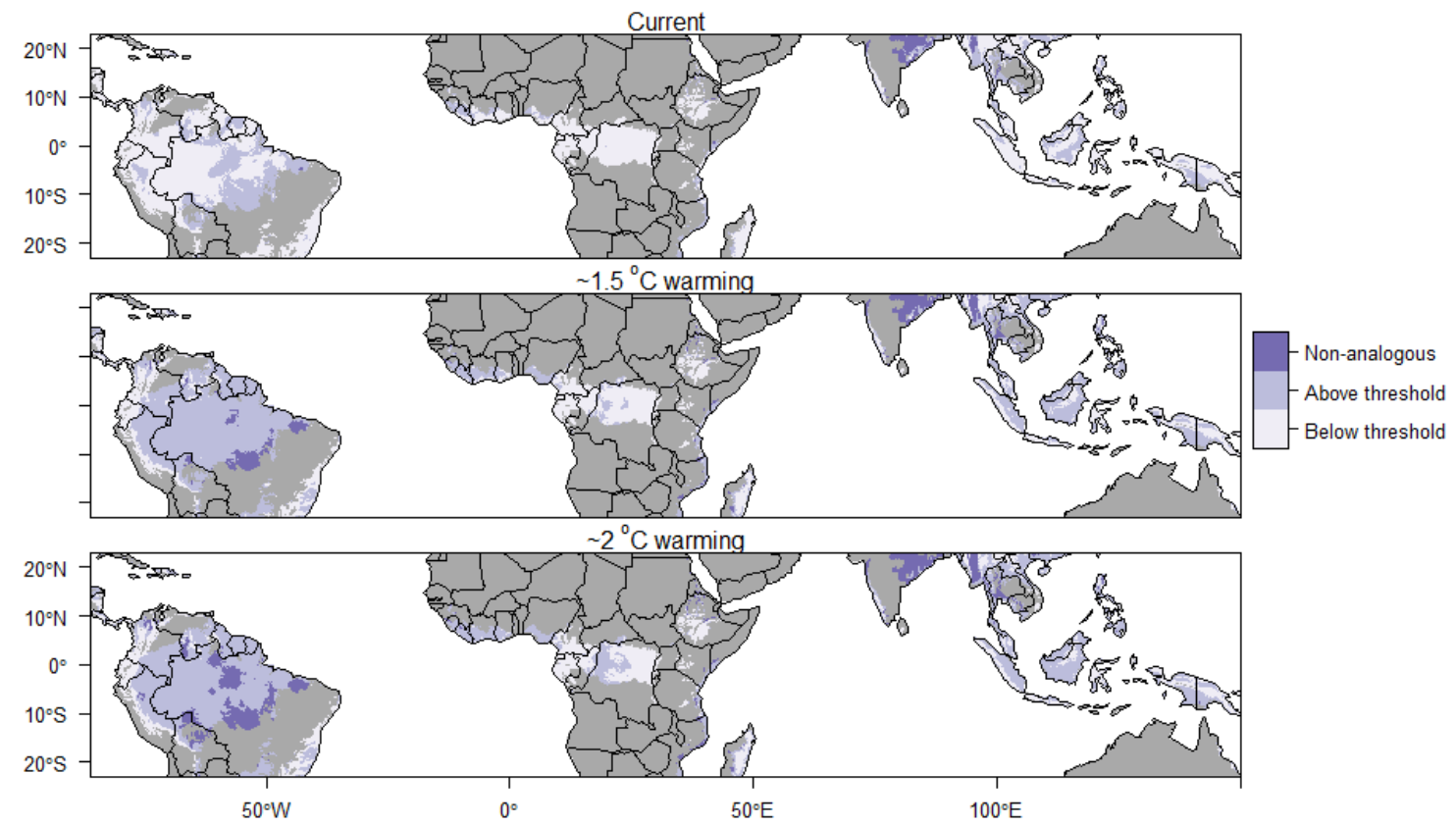

942

943 Figure S13 Areas of the biome above or below the $32.2^{\circ} \mathrm{C}$ threshold, above which carbon stocks

944 decline more rapidly with temperature, under current conditions and two warming scenarios (see Fig.

945 4). Areas warmer than any currently observed in our dataset $\left(35.2^{\circ} \mathrm{C}\right)$ are also shown (non-analogous conditions). Note that even the $1.5^{\circ} \mathrm{C}$ warming scenario pushes most South American forests above the $32.2^{\circ} \mathrm{C}$ threshold. 


\section{$\Delta$ Carbon stocks $\left(\mathrm{Mg} \mathrm{ha}^{-1}\right)$}

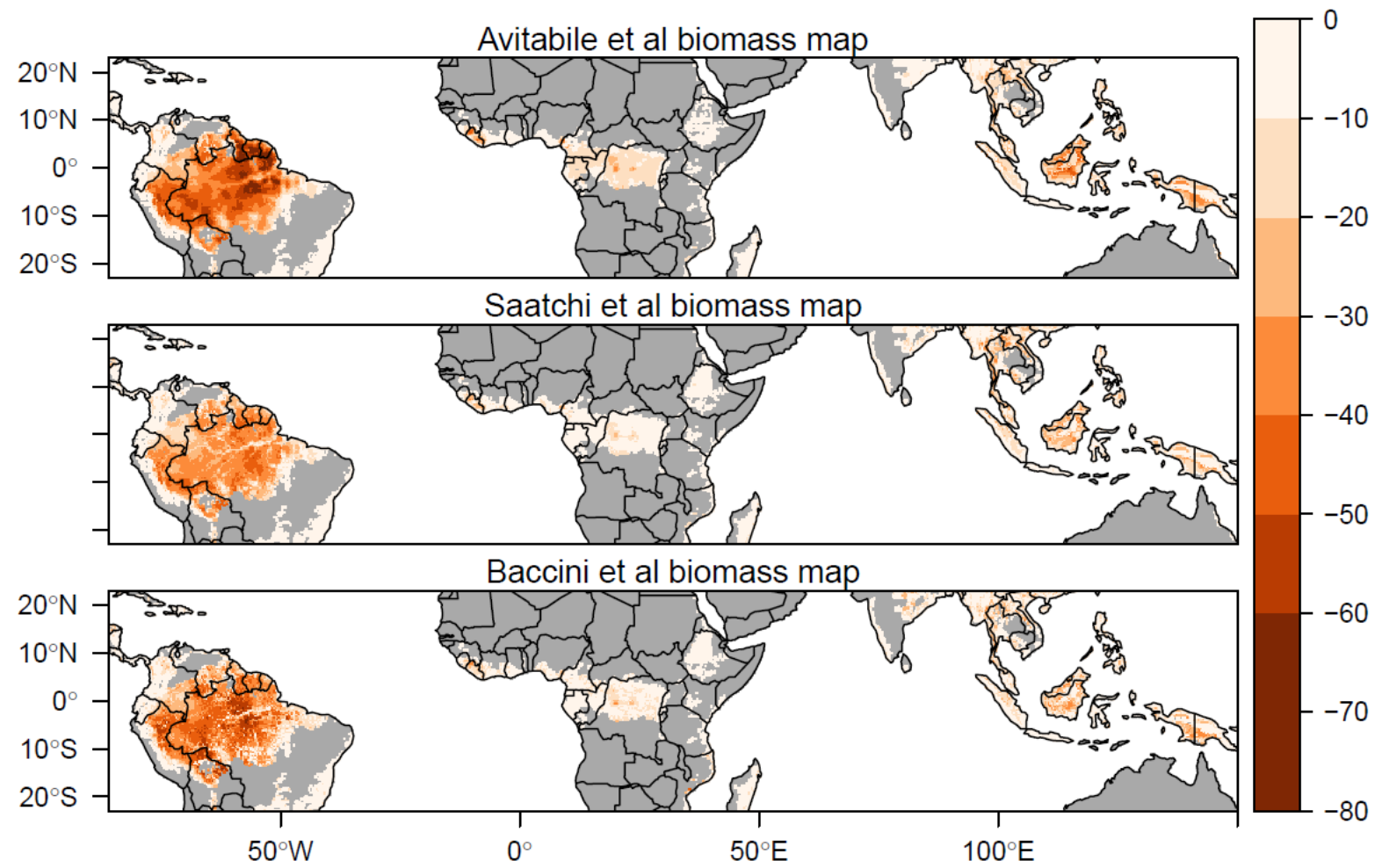

954 Figure S14. Effect of using earlier biomass reference maps for estimates of change in long-term

955 carbon stocks for global temperature increases of $\sim 2^{\circ} \mathrm{C}$. Using aboveground biomass stock maps from

956 Saatchi et al. (65) and Baccini et al. (66) predicted biome-wide reductions in biomass carbon stocks

957 are $24.0 \mathrm{Pg}(95 \% \mathrm{CI}=5.8-39.6)$ and $28.4 \mathrm{Pg}(95 \% \mathrm{CI}=16.1-37.5)$ respectively. Under the

$9581.5^{\circ} \mathrm{C}$ warming scenario these are $18.4 \mathrm{Pg}(5.8-30.5)$ and $21.1 \mathrm{Pg}(10.2-29.4)$ respectively. Results

959 in the main text use the 2016 Avitabile et al. baseline map (30) - see methods for justification. 


\section{$\Delta$ Carbon stocks $\left(\mathrm{Mg} \mathrm{ha}^{-1}\right)$}

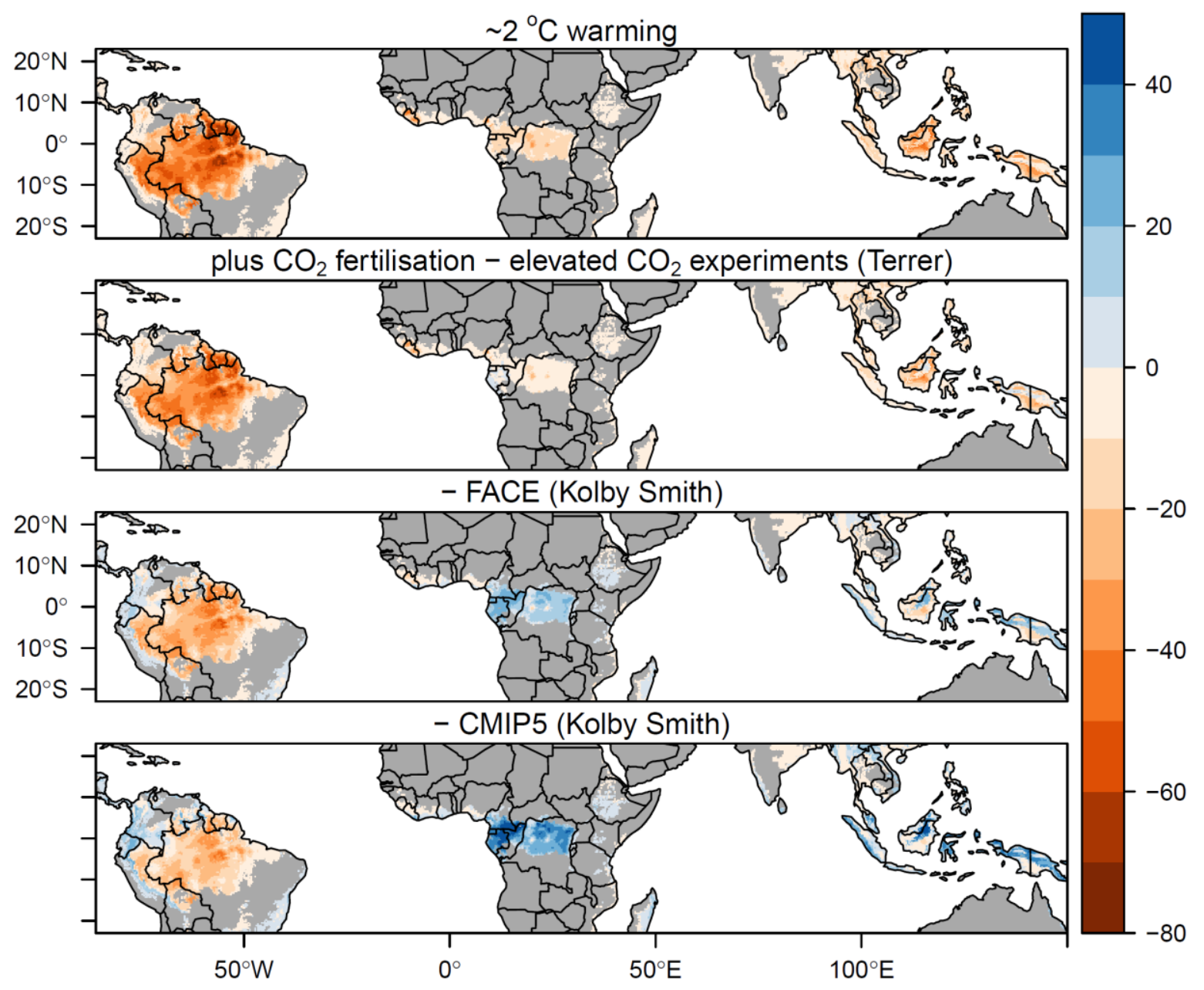

961

Figure S15. Predicted long-term change in aboveground carbon stocks under $\sim 2^{\circ} \mathrm{C}$ global warming,

based on either temperature effects alone or when also accounting for carbon dioxide growth

stimulation. $\mathrm{CO}_{2}$ fertilisation effects on equilibrium biomass levels were obtained from a recent experiments (Kolby Smith et al. (74)) and CMIP5 earth system models (Kolby Smith et al. (74)).

Depending on their strength, $\mathrm{CO}_{2}$ effects either partially or fully ameliorate the biome-wide negative effects of increasing temperatures on biomass carbon stocks (Table S3), but these carbon stocks are predicted to decline over much of Amazonia even under the strongest $\mathrm{CO}_{2}$ effect considered. 
Table S1. Climate variables selected for analysis and mechanisms by which they can affect carbon stocks.

\begin{tabular}{|c|c|c|}
\hline $\begin{array}{l}\text { Climate } \\
\text { property }\end{array}$ & Variable selected for analysis & Mechanism to affect carbon stocks \\
\hline $\begin{array}{l}\text { Daytime } \\
\text { temperature }\end{array}$ & $\begin{array}{l}\text { Maximum temperature in the } \\
\text { warmest month }{ }^{1}\end{array}$ & $\begin{array}{l}\text { High daytime temperatures exceed photosynthesis optima ( } 80) \text {, increase evaporative stress, causing } \\
\text { stomatal closure and reducing time for photosynthesis }(26) \text { and increase risk of mortality through } \\
\text { hydraulic failure and/or carbon starvation (23). }\end{array}$ \\
\hline $\begin{array}{l}\text { Night-time } \\
\text { temperature }\end{array}$ & $\begin{array}{l}\text { Mean daily minimum } \\
\text { temperature }\end{array}$ & $\begin{array}{l}\text { Respiration rate increases with temperature so proportion of carbon taken through photosynthesis that is } \\
\text { allocated to wood should decline with temperature }(81) \text {. Increased respiration cost could also reduce tree } \\
\text { longevity ( } 23) \text {. As respiration occurs day and night, and photosynthesis only in the day, nighttime } \\
\text { temperature should better reflect respiration effects and daytime temperature better reflect photosynthesis } \\
\text { effects. }\end{array}$ \\
\hline $\begin{array}{l}\text { Moisture } \\
\text { availability }\end{array}$ & $\begin{array}{l}\text { Precipitation in the driest } \\
\text { quarter }^{2}\end{array}$ & $\begin{array}{l}\text { Moisture availability could limit photosynthesis and hence carbon gains, with stomata closing when } \\
\text { moisture availability is limiting. The risk of mortality through hydraulic failure or carbon starvation is } \\
\text { higher when moisture is limiting (23), and this could also set a limit on potential tree size and hence tree } \\
\text { longevity. }\end{array}$ \\
\hline $\begin{array}{l}\text { Light } \\
\text { availability }\end{array}$ & Cloud frequency & $\begin{array}{l}\text { Increased photosynthesis and hence AGWP when light availability is greatest (i.e. cloud cover is low) } \\
\text { (82). Alternatively, light availability could have a negative effect due to high evapotranspiration stress } \\
\text { when cloud cover is low. }\end{array}$ \\
\hline Wind speed & Mean wind speed & $\begin{array}{l}\text { Carbon stocks are expected to be lower where physical damage through wind throw or breakage is } \\
\text { higher, as carbon is removed more quickly from the system through mortality }(83) \text {. But there is potential } \\
\text { for greater carbon gains if forests are more dynamic. }\end{array}$ \\
\hline
\end{tabular}

${ }^{1}$ Mean daily temperature in the warmest month (bio5) was selected instead of mean daily maximum temperature as it was more strongly decoupled from other climate variables. VPD could also represent some of these effects, but was too strongly correlation with maximum temperature to include as an independent variable.

${ }^{2}$ Moisture availability could also be represented by MCWD (maximum cumulative water deficit) or total precipitation, but only one of the three variables could be included in the model due to collinearity. MCWD was excluded as it is zero truncated, so less amenable to regression fitting. 
Supporting information for Sullivan et al.

979 Table S2. Coefficients of model-averaged general linear models of carbon stocks, gains and residence time as a function of climate, soil, continent and spatial 980 autocorrelation. Coefficients are AIC weighted averages across models with $\Delta \mathrm{AIC}<4$ from the best performing model; variables are given a score of zero if

981 they did not appear in a model. NA indicates that a term did not occur in any model in this set. MEM1-8 are spatial eigenvectors.

\begin{tabular}{|c|c|c|c|c|c|c|c|c|c|c|c|c|}
\hline \multirow[b]{2}{*}{ Variable } & \multicolumn{4}{|c|}{ Carbon stocks } & \multicolumn{4}{|c|}{ Carbon gains } & \multicolumn{4}{|c|}{ Carbon residence time } \\
\hline & Estimate & SE & $\mathrm{Z}$ & $\mathrm{P}$ & Estimate & SE & $\mathrm{Z}$ & $\mathrm{P}$ & Estimate & SE & $\mathrm{Z}$ & $P$ \\
\hline Intercept - Africa & 4.986 & 0.010 & 476.9 & $<0.001$ & 0.571 & 0.525 & 1.09 & 0.278 & 3.909 & 0.688 & 5.67 & $<0.001$ \\
\hline Minimum temperature & 0.031 & 0.019 & 1.67 & 0.096 & -0.001 & 0.007 & 0.18 & 0.861 & 0.019 & 0.022 & 0.88 & 0.381 \\
\hline $\begin{array}{l}\text { Maximum temperature, warmest } \\
\text { month }\end{array}$ & -0.089 & 0.022 & 4.11 & $<0.001$ & -0.060 & 0.017 & 3.47 & $<0.001$ & -0.001 & 0.015 & 0.10 & 0.924 \\
\hline Precipitation, driest quarter & 0.045 & 0.018 & 2.54 & 0.011 & -0.001 & 0.008 & 0.14 & 0.887 & 0.061 & 0.023 & 2.70 & 0.007 \\
\hline Cloud frequency & 0.002 & 0.008 & 0.24 & 0.814 & -0.006 & 0.011 & 0.54 & 0.592 & 0.025 & 0.021 & 1.17 & 0.241 \\
\hline Wind speed & 0.004 & 0.012 & 0.38 & 0.705 & 0.016 & 0.020 & 0.78 & 0.437 & -0.004 & 0.015 & 0.24 & 0.807 \\
\hline Soil texture (\% clay) & 0.021 & 0.017 & 1.26 & 0.208 & -0.005 & 0.011 & 0.49 & 0.628 & 0.040 & 0.018 & 2.17 & 0.030 \\
\hline Soil fertility (CEC) & -0.003 & 0.009 & 0.34 & 0.732 & 0.005 & 0.011 & 0.51 & 0.613 & -0.012 & 0.017 & 0.70 & 0.486 \\
\hline MEM1 & 0.115 & 0.014 & 7.96 & $<0.001$ & 0.319 & 0.559 & 0.57 & 0.569 & 0.375 & 0.734 & 0.51 & 0.610 \\
\hline MEM2 & 0.098 & 0.017 & 5.67 & $<0.001$ & 0.083 & 0.273 & 0.30 & 0.762 & 0.286 & 0.359 & 0.80 & 0.427 \\
\hline MEM3 & -0.025 & 0.014 & 1.84 & 0.065 & 0.014 & 0.041 & 0.34 & 0.735 & 0.007 & 0.054 & 0.12 & 0.904 \\
\hline MEM4 & -0.021 & 0.011 & 1.84 & 0.066 & -0.038 & 0.020 & 1.84 & 0.066 & -0.002 & 0.027 & 0.07 & 0.945 \\
\hline MEM5 & 0.027 & 0.011 & 2.46 & 0.014 & 0.020 & 0.015 & 1.33 & 0.182 & 0.020 & 0.020 & 0.98 & 0.327 \\
\hline MEM6 & 0.017 & 0.011 & 1.56 & 0.118 & 0.025 & 0.011 & 2.34 & 0.019 & -0.014 & 0.014 & 1.05 & 0.293 \\
\hline MEM7 & 0.010 & 0.011 & 0.93 & 0.353 & -0.017 & 0.010 & 1.61 & 0.107 & 0.036 & 0.014 & 2.57 & 0.010 \\
\hline MEM8 & -0.072 & 0.013 & 5.64 & $<0.001$ & 0.057 & 0.012 & 4.91 & $<0.001$ & -0.127 & 0.016 & 7.80 & 0.000 \\
\hline Asia & NA & & & & 0.380 & 0.542 & 0.70 & 0.485 & -0.753 & 0.683 & 1.10 & 0.271 \\
\hline Australia & NA & & & & -0.173 & 0.390 & 0.44 & 0.658 & 0.006 & 0.516 & 0.01 & 0.990 \\
\hline South America & NA & & & & 0.643 & 1.164 & 0.55 & 0.582 & 0.542 & 1.530 & 0.35 & 0.724 \\
\hline
\end{tabular}


Supporting information for Sullivan et al.

983

984

985

986

987

988

989 temperature effects alone) are shown in parentheses.

\begin{tabular}{|c|c|c|}
\hline \multirow{2}{*}{$\mathrm{CO}_{2}$ effect } & \multicolumn{2}{|c|}{ Change in biomass carbon stocks $(\mathrm{Pg})$} \\
\hline & $\begin{array}{l}\sim 1.5^{\circ} \mathrm{C} \text { warming } \\
\left(443 \mathrm{ppm} \mathrm{CO} \mathrm{CO}_{2}\right)\end{array}$ & $\begin{array}{l}\sim 2^{\circ} \mathrm{C} \text { warming } \\
\left(487 \mathrm{ppm} \mathrm{CO}_{2}\right)\end{array}$ \\
\hline None & $-26.9(-38.4--15.8)$ & $-35.3(-49.0--20.9)$ \\
\hline $\begin{array}{l}\text { Terrer et al. elevated } \mathrm{CO}_{2} \\
\text { experiments }\end{array}$ & $-22.0(-33.0--9.9)$ & $-26.3(-37.6--11.5)$ \\
\hline $\begin{array}{l}\text { Kolby Smith et al. FACE } \\
\text { experiments }\end{array}$ & $-6.2(-16.8-7.7)$ & $-9.9(-24.3-3.9)$ \\
\hline $\begin{array}{l}\text { Kolby Smith et al. CMIP5 } \\
\text { models }\end{array}$ & $3.9(-8.3-12.6)$ & $2.0(-11.9-19.8)$ \\
\hline
\end{tabular}

Table S3. Predicted biome-wide changes in long-term biomass carbon stocks (scaled to include root biomass) under global temperature increases of $\sim 1.5^{\circ} \mathrm{C}$ and $\sim 2^{\circ} \mathrm{C}$. Changes are based on temperature effects alone, and when also accounting for the effect of increased $\mathrm{CO}_{2}$ concentrations on tree growth. $\mathrm{CO}_{2}$ effects were obtained from a synthesis of results of elevated $\mathrm{CO}_{2}$ experiments (Terrer et al. (77)), free-air $\mathrm{CO}_{2}$ enrichment (FACE) experiments (Kolby Smith et al. (74)) and CMIP5 earth system models (Kolby Smith et al. (74)). 95\% confidence intervals around changes (based on uncertainties in 
Supporting information for Sullivan et al.

991

992

993 